\title{
Identification and characterization of expression profiles of neuropeptides and their GPCRs in the swimming crab, Portunus trituberculatus
}

\author{
Shisheng Tu ${ }^{1}$, Rui Xu ${ }^{1}$, Mengen Wang ${ }^{1}$, Xi Xie $^{1}$, Chenchang Bao ${ }^{\text {Corresp., } 1}$, Dongfa Zhu ${ }^{\text {Corresp. } 1}$ \\ ${ }^{1}$ School of Marine Science, Ningbo University, Ningbo, Zhejiang, China \\ Corresponding Authors: Chenchang Bao, Dongfa Zhu \\ Email address: baochenchang@nbu.edu.cn, zhudongfa@nbu.edu.cn
}

Neuropeptides and their G protein-coupled receptors (GPCRs) regulate multiple physiological processes. Currently, little is known about the identity of native neuropeptides and their receptors in Portunus trituberculatus. This study employed RNAsequencing and reverse transcription-polymerase chain reaction (RT-PCR) techniques to identify neuropeptides and their receptors that might be involved in regulation of reproductive processes of $P$. trituberculatus. In the central nervous system transcriptome data, 47 neuropeptide transcripts were identified. In further analyses, the tissue expression profile of 32 putative neuropeptide-encoding transcripts was estimated. Results showed that the 32 transcripts were expressed in the central nervous system and 23 of them were expressed in the ovary. A total of 47 GPCR-encoding transcripts belonging to two classes were identified, including 39 encoding GPCR-A family and 8 encoding GPCR-B family. In addition, we assessed the tissue expression profile of 33 GPCRs (27 GPCR-As and 6 GPCR-Bs) transcripts. These GPCRs were found to be widely expressed in different tissues. Similar to the expression profiles of neuropeptides, 20 of these putative GPCRencoding transcripts were also detected in the ovary. This is the first study to establish the identify of neuropeptides and their GPCRs in $P$. trituberculatus, and provide information for further investigations into the effect of neuropeptides on the physiology and behavior of decapod crustaceans. 
1 Identification and characterization of expression profiles of neuropeptides and their

2 GPCRs in the swimming crab, Portunus trituberculatus.

3

4

5

8 Corresponding Author:

9 Chenchang Bao

10 No.169 Qixing South Road, Ningbo, Zhejiang Province, 315832, China.

11 Email address: baochenchang@nbu.edu.cn

12 Dongfa Zhu

13 No.169 Qixing South Road, Ningbo, Zhejiang Province, 315832, China.

14 Email address: zhudongfa@nbu.edu.cn

Abstract: Neuropeptides and their G protein-coupled receptors (GPCRs) regulate multiple physiological processes. Currently, little is known about the identity of native neuropeptides and their receptors in Portunus trituberculatus. This study employed RNA-sequencing and reverse transcription-polymerase chain reaction (RT-PCR) techniques to identify neuropeptides and their receptors that might be involved in regulation of reproductive processes of $P$. trituberculatus. In the central nervous system transcriptome data, 47 neuropeptide transcripts were identified. In further analyses, the tissue expression profile of 32 putative neuropeptide-encoding transcripts was estimated. Results showed that the 32 transcripts were expressed in the central nervous system and 23 of them were expressed in the ovary. A total of 47 GPCR-encoding transcripts belonging to two classes were identified, including 39 encoding GPCR-A family and 8 encoding GPCR-B family. In addition, we assessed the tissue expression profile of 33 GPCRs (27 GPCRAs and 6 GPCR-Bs) transcripts. These GPCRs were found to be widely expressed in different tissues. Similar to the expression profiles of neuropeptides, 20 of these putative GPCR-encoding transcripts were also detected in the ovary. This is the first study to establish the identify of neuropeptides and their GPCRs in P. trituberculatus, and provide information for further crustaceans.

Keywords: Neuropeptides, GPCRs, expression, Portunus trituberculatus 
36

37

38

39

40

41

42

43

44

45

46 47

48

49

50

51

52

53

54

55

56

57

58

59

60

61

62

63

64

65

66

67

68

69

70

\section{Introduction}

Numerous neuropeptides have pleiotropic function molecules that are involved in reproduction, development, stress response, immune response, and metabolism (Buratti et al., 2013; Chen et al., 2018; Liu et al., 2019b; Xu et al., 2020; Yang et al., 2014). Several neuropeptides play an essential role in controlling ovarian maturation. These neuropeptides include molt-inhibiting hormone (MIH) (Luo et al., 2015), short neuropeptide F (sNPF) (Bao et al., 2018a), red pigment concentrating hormone (RPCH) (Zeng et al., 2016) and neuropeptide F(NPF) (Tinikul et al., 2017). Notably, MIH and NPF may be promising candidates to induce spawning in Litopenaeus vannamei (González et al., 2020) and Macrobrachium rosenbergii (Tinikul et al., 2017), respectively. Although the draft genome of P. trituberculatus is available, the molecular mechanisms of neuropeptides that regulate reproduction are unknown (Tang et al., 2020).

Neuropeptides predominantly bind to G protein-coupled receptors (GPCRs) to exhibit their functions (Sharabi et al., 2016). GPCRs are the largest gene family of transducing cell surface proteins. The family consists of an extracellular N-terminus, a region of seven transmembrane (7-TM) domains, and an intracellular C- terminus (Davies et al, 2007). The arthropod GPCR gene family is subdivided into 4 classes, including rhodopsin-like receptors (class A), secretinlike receptors (class B), metabotropicglutamate-like receptors (class C), and atypical GPCRs based on sequence motifs (Brody et al., 2000). It is challenging to identify GPCRs in related species because these sequences generally do not share as high an overall sequence homology as neuropeptides do (Caers et al., 2012). In decapod crustaceans, several efforts had been made to identify neuropeptide GPCR genes, however, only eight species of GPCRs, including Scylla paramamosain (Bao et al., 2018b), Sagmariasus verreauxi (Buckley et al., 2016), Panulirus argus (Christie 2020), Carcinus maenas (Oliphant et al., 2018), Paranephrops zealandicus (Oliphant et al., 2020), Macrobrachium nipponense (Sun et al., 2020), Penaeus monodon (Viet Nguyen et al., 2020) and Nephrops norvegicus (Nguyen et al., 2018), have been reported in previous studies or deposited in public databases. Many putative neuropeptide receptors have been tentatively identified on the basis of homology, but only a handful have been functionally deorphaned in crustaceans (Alexander et al., 2018; Bao et al., 2018a; Bao et al., 2018b).Therefore, it is necessary to identify GPCRs to explore the function of neuropeptides in P. trituberculatus.

7 Advances in Next Generation Sequencing (NGS), has resulted in identification of neuropeptide repertoire of several decapod species, such as S. paramamosain (Bao et al., 2015), Cherax quadricarinatus (Nguyen et al., 2016), N. norvegicus (Nguyen et al., 2018), C. maenas (Oliphant et al., 2018), Procambarus clarkia (Veenstra 2015), and M. nipponense (Sun et al., 
71 2020), based on transcriptome databases. However, currently, no information is available for 72 identification of neuropeptides and GPCRs in P. trituberculatus. Therefore, identification of 73 neuropeptides and GPCRs represents an important step to unravel the roles of these molecules 74 involved in reproduction.

75 The swimming crab, Portunus trituberculatus (Crustacea: Decapoda: Brachyura) is 76 common edible crab. It is widely distributed in the estuary and coastal waters of Korea, Japan, 77 China, and Southeast Asia (Meng et al., 2020). The only neuropeptides reported in this species 78 include CHH (Xie et al., 2014), MIH (Wang et al., 2013), and CCAP (Sun et al., 2019). In 79 addition, no studies have reported the $P$. trituberculatus neuropeptidome. In this study, a total of 8047 transcripts encoding putative neuropeptides and 47 predicted GPCR-encoding transcripts in $P$. 81 trituberculatus were identified based on the CNS transcriptome database. Potential 82 neuropeptides and GPCRs were screened for tissue spatial expression by Reverse transcription83 polymerase chain reaction (RT-PCR) and showed that their roles might be involved in regulation 84 of reproduction in $P$. trituberculatus. The findings of this study provide insights into neuropeptide/GPCR signaling pathways that regulate reproduction in P. trituberculatus.

\section{Materials and methods}

88

\section{Animals}

Crab study protocol was approved by the Animal Ethics Committee of Ningbo University.

Healthy swimming crabs (female:300-350g;male:200-250g) were purchased from the local fisheries market in Zhenhai District, Ningbo City, Zhejiang Province, China. All crabs are in the intermolt stage by observing their morphological characteristics as previously described (Shen et al., 2011). Three female and two male crabs were randomly selected and anesthetized on ice for 20 minutes before dissection. The cerebral ganglia, eyestalk ganglia and ventral ganglia were then removed surgically, frozen immediately in liquid nitrogen, and stored at $-80^{\circ} \mathrm{C}$ for further use.

\section{Sample preparation and Transcriptome sequencing}

Five individual samples from each crab were pooled for extraction of total RNA using Trizol Reagent (Takara) following the manufacturer's instructions. Genomic DNA was removed using DNase I (Takara). Integrity and purity of RNA were determined using Agilent Bioanalyzer 2100 system (Agilent Technologies, CA, USA) and the NanoPhotometer ${ }^{\circledR}$ spectrophotometer (IMPLEN, CA, USA), respectively. High-quality RNA samples (OD260/280 $=1.8-2.2$, OD260/230 > 2.0) were used for construction of sequencing library. Sequencing libraries were generated using NEBNext ${ }^{\circledR}$ Ultra $^{\mathrm{TM}}$ RNA Library Prep Kit for Illumina ${ }^{\circledR}(\mathrm{NEB}$, 
105 USA), following the manufacturer's recommendations. Index codes were used to attribute 106 sequences to each sample. cDNA libraries were then sequenced on an Illumina Hiseq 4000 107 platform (Illumina, USA) and paired-end reads were generated. Raw reads were processed 108 through a Perl program for quality control. Clean data were obtained by removing reads 109 containing adapter, reads containing ploy-N and low-quality reads from raw data. In addition, 110 Q20, Q30, GC-content and sequence duplication level of the clean data were calculated. 111 Transcriptome assembly was performed usingTrinity with min_kmer_cov set to 2 and all other 112 parameters set default (Grabherr et al., 2011).

\section{Bioinformatic Analysis of neuropeptides and their receptors}

Peptides and their receptors were obtained from swimming crab, one transcriptome was assembled from all the ganglia combined. A well-established workflow was used to identify peptides (Bao et al., 2015). NCBI BLAST was used to re-validate the sequences. The nucleotide

117 sequences were then converted to amino acids using Expasy translate tool available online 118 (https://web.expasy.org/translate/) and open reading frames (ORFs) were obtained using ORF finder webserver (https://www.ncbi.nlm.nih.gov/orffinder). All predicted precursors were assessed for the presence of a signal peptide using SignalP5.0 webserver (http://www.cbs.dtu.dk/services/SignalP/). Cysteine to cysteine disulfide bridges were predicted using a webserver (http://disulfind.dsi.unifi.it/). Structures of mature peptides were predicted using a well-established workflow (Christie 2014; Christie \& Chi., 2015) and prohormone cleavage sites prediction based on the standards defined by Veenstra (Veenstra 2000). Other post-translational modifications, including cyclization of $\mathrm{N}$-terminal glutamine or glutamic acid residues and $\mathrm{C}$-terminal amidation at glycine residues were predicted through homologous comparison to known arthropod peptides (Bao et al., 2020; Bao et al., 2015; Christie 2014; Christie 2016a; Christie 2016b; Christie 2020; Christie \& Chi., 2015; Christie et al., 2017; Johnson et al., 2015; Nguyen et al., 2018; Vaudry et al., 2014; Veenstra 2015; Veenstra 2016; Wegener et al., 2015; Xu et al., 2015). Illustrator for Biological Sequences (IBS) software was used to generate schematic diagrams of protein domain structures (Ren et al., 2009). Multiple sequence alignments were done using ClustalX. Multiple alignment files were imported to Jalview2.10.5 software to identify conserved sequence motifs and the LOGO.

GPCR transcript sequences obtained from CNS transcriptomes of $P$. trituberculatus, were translated using the translate tool in ExPASy and assessed for completeness (predicted protein sequences $<150$ amino acids in length were deemed too short for accurate vetting and were not reported in this article) (Christie et al., 2019). The protein sequences were revalidated by BLAST. GPCR sequences were identified using GPCRHMM webserver (https://gpcrhmm.sbc.su.se/) and only sequences containing seven transmembrance domains 
141 phylogenetic analysis, 7TM domains of all GPCRs (those from this study and previously 142 characterized receptors) were extracted and compiled into one list (Supplementary Material 1).

143 Phylogenetic trees were constructed using SeaView software (Gouy et al., 2009) (PhyML 144 algorithm) and visualized with Figtree v1.4.3and Adobe Photoshop CS (version 6.0).

145 Tissue expression of neuropeptides and determination of GPCRs of interest by RT-PCR

146 To explore tissue expression of neuropeptide transcripts and their GPCR transcripts, nine 147 tissues, including cerebral ganglia, eyestalk ganglia, gill, hepatopancreas, heart, muscle, ovary, 148 ventral ganglia, and Y-organ were harvested from wild female P. trituberculatus ( $\mathrm{n}=3)$. All crabs 149 are in ovarian development stage III based on the gonadosomatic index (GSI\%, ovary 150 weight $\times 100 /$ body weight) and external features of the ovary (Wu et al., 2007). Total RNA from 151 tissues was extracted using RNA-Solv Reagent (Omega Biotek, USA), following the 152 manufacturer's protocol. Total RNA ( $\sim \mu \mathrm{g}$ RNA per tissue) was used for cDNA synthesis using 153 HiFiScript gDNA Removal cDNA Synthesis Kit (CWBIO, China). A total of 32 neuropeptide 154 transcripts, 33 GPCR transcripts, and one housekeeping gene were chosen for RT-PCR. Gene155 specific primers were designed using primer 5.0 software based on the CDS of transcripts. 156 Primers used in this article are presented in Supplementary Material 2. RT-PCRs 157 amplifications were carried out using a touch-down PCR to allow maximum PCR products to be 158 amplified with minimal non-specific signal., PCR settings were as follows: $95^{\circ} \mathrm{C}$ for 3 minutes, 159 followed by 35 cycles of touch down, $95^{\circ} \mathrm{C}$ for 30 seconds, $62-57^{\circ} \mathrm{C}$ for 30 seconds (with $1^{\circ} \mathrm{C}$ 160 decrease for each of the first 6 cycles) and $72^{\circ} \mathrm{C}$ for 20 seconds. PCR products were separated on $1612.0 \%$ agarose gel electrophoresis and visualized using GelRed (Biotium).

162

163 Results and Discussion

164 Identification of neuropeptide transcript and peptide prediction

165 Cerebral ganglia, eyestalk ganglia, and ventral ganglia, each consisting of two males and 166 three females, were used for transcriptome sequencing to identify neuropeptides in $P$. 167 trituberculatus. All raw reads were submitted to the NCBI SRA under Accession: BioProject No. 168 PRJNA707143 (SRR13870345, SRR13870346 and SRR13870347). Quality, de novo assembly 169 statistics and annotation summary data are shown in Supplementary Material 3. A total size of $170124,237,692 \mathrm{bp}$ of the assembled transcripts were obtained with an average size of $1784 \mathrm{bp}$ and 171 half of the contigs N50 were at least 3,185 bp long. The shortest and longest assembled 172 sequences were 301 and 28,583 bp, respectively. A total of 47 predicted neuropeptide transcripts 173 and 47 peptide GPCR transcripts were identified using bioinformatics tools, containing 39 A174 family GPCRs (Pt-GPCR-A) and 8 B-family GPCRs (Pt-GPCR-B), from central nervous system 
175 (CNS, including cerebral ganglia, eyestalk ganglia and ventral ganglia) of P. trituberculatus. 176 Most of the neuropeptides were previously identified in other crustacean and/or insect species 177 (Table 1). Predicted peptides included: adipokinetic hormone corazonin-like peptide (ACP), 178 agatoxin-like peptide (ALP), allatostatin A (AST-A), allatostatinB (AST-B), allatostatin C (AST179 C), allatostatin CCC (AST-CCC), bursicon, crustacean cardioactive peptide (CCAP), crustacean 180 hyperglycemic hormone $(\mathrm{CHH})$ /molt-inhibiting hormone $(\mathrm{MIH})$, CCHamide $(\mathrm{CCH})$, crustacean 181 female sex hormone (CFSH), corazonin (Crz), CNMamide (CNM), CRF-like DH44, calcitonin182 like diuretic hormone31 (DH31), Carcikinin/ecdysis triggering hormone (ETH), elevenin, 183 glycoprotein-A2 (GPA2), glycoprotein-B5 (GPB5), GSEFLamide, HIGSLYRamide, insulin-like 184 peptide (ILP), kinin, myosuppressin, neuroparsin (NP), neuropeptide F (NPF), short 185 neuropeptide F (sNPF), vasopressin, orcokinin, pigment-dispersing hormone (PDH), proctolin, 186 pyrokinin, red pigment-concentrating hormone (RPCH), RYamide, SIFamide, sulfakinin (SK), 187 tachykinin (TK), Trissin, and Natalisin. Most of these neuropeptides are present in related 188 crustaceans, such as $S$. paramamosain (Bao et al., 2015), S. olivacea (Christie 2016b) and C. 189 maenas (Oliphant et al., 2018). Sequence alignments between the precursors from these species 190 showed that all peptides, especially the mature peptides, are conserved. For instance, the 191 predicted mature peptides of Carcikinin (DAGHFFAETPKHLPRIamide), CCAP 192 (PFCNAFTGCamide), and AST-C (pQIRYHQCYFNPISCF) were highly conserved. This suggests that prediction of the putative peptide sequences in this study are mostly accurate.

Adipokinetic hormone-corazonin like peptide (ACP)/Agatoxin-like peptide (ALP)/Allatostatin (AST)/Bursicon and CCAP

196

A putative ACP precursor was predicted from the de novo transcriptome of $P$. 197 trituberculatus central nervous system. The predicted encoded complete ACP precursor of 101 amino acids (aa), with 12 aa mature peptides, pQITFSRSWVPQamide (Supplementary Material 4 and Figure 1A), is a highly conserved decapod ACP peptide (Christie 2016a; Christie 2016b; Christie \& Chi 2015). One Pt-ALP transcript was identified in the current de 201 novo transcriptome assembly of $P$. trituberculatus. The transcript encodes for 113 aa protein, 202 with 2 laa signal peptide. PtALP has two cleavage sites $\left(\mathrm{K}_{66} \mathrm{~K}\right.$ and $\left.\mathrm{K}_{113}\right)$, which if processed 203 results in cleavage of the mature peptide 204 WRSCIRRGGACDHRPNDCCYNSSCRCNLWGTNCRCQRMGIFQQWamide. It has 8 205 cysteine residues that presumably allow for the formation of four identically positioned disulfide 206 bridges (Supplementary Material 4 and Figure 1B), and amidated C-terminus which are characteristic of decapod species (Christie et al., 2020). Based on their distinct structural differences, allatostatins are classified into three different families (A-type, B-type and C-type) (Stay et al., 2007; Verlinden et al., 2015) In crustaceans, the existence of AST-As, AST-Bs and 
211 et al., 2005), Homarus americanus (Ma et al., 2009b), respectively. A total of 4 transcripts were 212 detected that encoded for the precursor of AST family including, AST-A, AST-B, AST-C, and 213 AST-CCC. The precursor AST-A had a region of the predicted signal peptide (27 aa), followed 214 by 35 predicted peptides separated by multiple dibasic cleavage sites. The conserved motif 215 recorded was XYXFGLamide (Supplementary Material 4 and Figure 1C), such as 216 AGPYSFGLamide sequence, which is common insects and other crustaceans in the AST-A 217 family (Bao et al., 2015; Christie et al., 2010b; Stay \& Tobe 2007). A single transcript was 218 observed in the transcriptome assembly. The putative neuropeptide precursor encoded 314 aa 219 and has a 19 aa signal peptide. This precursor had 11 predicted mature peptides, containing the 220 conserved XWXXXXGXWamide motif (Supplementary Material 4 and Figure 1D), such as 221 AGWSSMRGAWamide sequence, which is a signature motif in AST-B family (Christie et al., 222 2010b). The predicted sequence of the AST-C precursor comprised 149 aa with a predicted 223 signal peptide of 21 aa. The predicted mature peptide had15aa, with a highly conserved PISCF 224 motif with pQIRYHQCYFNPISCF (a disulfide bridge between two cysteine residues) sequence 225 (Bao et al., 2020; Bao et al., 2015; Ma et al., 2009b; Nguyen et al., 2016). AST-CCC precursor 226 showed a 110aa complete sequence, 24aa single peptide and 15aa mature peptide 227 (Supplementary Material4 and Fig 1E). An AST-C-like peptide precursor, was also detected 228 in $P$. trituberculatus. The AST-CCC shares a conserved motif (SYWKQCAFNAVSCFamide) with the AST-C sequence (Supplementary Material 4 and Figure 1E). In crustaceans, the first isoform of burscion was identified from C. maenas (Ma et al., 2009a; Wilcockson et al., 2008). In the transcriptome assembly, two transcripts, which encoded bursicon alpha and bursicon beta, precursor of 148 aa and 141 aa, respectively, were obtained. The two precursors had a signal peptide, immediately followed by adjacent mature peptide with 11 conserved cysteine residues (Supplementary Material 4 and Figure 2A). The structures of the mature peptides were highly

235

236

237

238

239

240

241

242

243

244

245

246 conserved across other decapod crustaceans, such as Callinectes sapidus and P. argus (Christie 2020). CCAP was originally identified from C. maenas via reverse phase high-performance liquid chromatography (RP-HPLC) procedure (Stangier et al., 1987) and the first CCAP transcript was predicted in Daphnia pulex via transcriptomics (Gard et al., 2009). In this study, One transcript was predicted to encode CCAP precursor of 141 aa, containing a predicted signal peptide of 30 aa and two cleavage sites $\left(\mathrm{K}_{47} \mathrm{R}\right.$ and $\left.\mathrm{K}_{59} \mathrm{~K}\right)$. The peptide released a mature peptide with PFCNAFTGCamide (a disulfide bridge between two cysteine residues) motif sequence (Supplementary Material 4 and Figure 2B).

Crustacean hyperglycemic hormone (CHH)/Molt-inhibiting hormone (MIH)/Crustacean female sex hormone (CFSH)/CCHamide (CCH) and Corazonin (Crz)

$\mathrm{CHH}$ was first purified and sequenced from eyestalks of C. maenas (Kegel et al., 1989). In 2006, CHH splice variants have confirmed in C. sapidus (Choi et al., 2006). Two transcripts 
247 were identified to putatively encode complete CHH precursors with 139 aa and 135 aa. Pt-CHH1 248 and Pt-CHH2 are products of alternative splicing. All two complete sequences consist of 26 aa 249 signal peptide, a CHH-precursor-related peptide (CPRP) and CHH mature peptides with 71 aa 250 and 73 aa, respectively (Supplementary Material 4 and Figure 2C). The two mature peptides 251 had six cysteine residues, and the six cysteines were aligned (Figure 2C). Characteristics of 252 these peptides were similar as we previously studied (Xie et al., 2014). The first putative MIH 253 was isolated and sequenced in C. maenas (Klein et al., 1993). The predicted sequence of the 254 MIH precursor comprised 113 aa, with 35 aa signal peptide. The sequence lacked CHH-PRP and 255 had an additional conserved glycine in position 12 of the putative mature peptide $\left(\mathrm{Gly}_{12}\right)$ 256 (Supplementary Material 4 and Figure 2D). In addition, the mature peptide had six cysteine 257 residues and could form three disulfide bridges, which is a characteristic of $\mathrm{CHH}$ family. Two 258 transcripts of $\mathrm{CCH}$ precursors were identified in the de novo transcriptome assembly of $P$. 259 trituberculatus. The two transcripts encode for 189 aa and 126 aa, each with a signal peptide 260 (Supplementary Material 4 and Figure 3A). The conserved motif for Pt-CCHamide mature 261 peptide was XCXXY/FGHSCXGAHamide (a disulfide bridge between two cysteine residues), 262 which is conserved in other decapod species, such as C. quadricarinatus (Nguyen et al., 2016) 263 and $P$. clarkia (Veenstra 2015). CFSH was initially isolated from sinus glang (SG) of C. sapidus 264 via RP-HPLC chromatograms and subsequently cDNA was cloned in this species (Zmora et al., 265 2014). A putative CFSH transcript with partial C-terminus of 223 aa was predicted from the 266 central nervous system of $P$. trituberculatus. The precursor CFSH had a region of the predicted 267 signal peptide ( $22 \mathrm{aa}$ ) and a $\mathrm{K}_{55} \mathrm{R}$ cleavage site, followed immediately by the mature peptide of 268167 aa (Supplementary Material 4 and Figure 3B). The mature peptide had eight cysteine 269 residues, which were conserved in other decapod CFSHs (Veenstra 2016). The first Crz 270 sequence was identified in $C$. borealis via mass spectrometry (Li et al., 2003). Also, Crz 271 precursor have been identified via transcriptome analysis from L. vannamei (Ma et al., 2010) and 272 Daphnia carinata (Christie et al., 2010a). A single transcript was identified to putatively encode 273 complete Crz precursor with 117 aa. Crz precursor had a 19 aa signal peptide, followed 274 immediately by the mature peptide, and a $\mathrm{R}_{32} \mathrm{KR}$ cleavage site (Supplementary Material 4 and 275 Figure 3C). The conserved motif sequence of Crz mature peptide was 276 pQTFQYSRGWTNamide, a highly conserved Crz motif in other crustaceans and insects 277 (Alexander et al., 2018; Nguyen et al., 2016).

278 CNMamide(CNM)/CRF-like DH44/Calcitonin-like diuretic hormone 31(DH31)/ 279 Carcikinin/ecdysis triggering hormone(ETH) and Elevenin

280 A CNMamide transcript was present in the assembly of $P$. trituberculatus. The precursor 281 putatively comprised 193 aa with a 30 aa predicted signal peptide. A 10 aa C-terminal amidated 282 CNMamide mature peptide is released after cleavage of two dibasic cleavage sites 
283 (Supplementary Material 4 and Figure 3D). The predicted mature peptide, 284 VMCHFKICNMamide (a disulfide bridge between two cysteine residues) is conserved in other 285 crustacean species (Veenstra 2015; Veenstra 2016). A single transcript was identified which 286 encoded a putative CRF-like DH44 precursor. This transcript encodes a 321 aa full-length 287 protein with a 19 aa predicted signal peptide (Supplementary Material 4 and Figure 3E). This 288 precursor has a 45 aa mature peptide, with the sequence, 289 NSGLSLSIDASMKVLREALYLEIARKKQRQQLQRAQHNKALLNTIamide, which is

290

291

292

293

294

295

296

297

298

299

300

301

302

303

304

305

306

307

308

309

310

311

312

313

314

315

316

317

318 conserved in other decapod species, such as H. americanus (Christie et al., 2017) and $M$. rosenbergii (Wegener et al., 2015). The first DH31 has been identified from D. pulex via transcriptomics (Gard et al., 2009). The predicted sequence of the DH31 precursor comprised 111 aa, with a predicted signal peptide of 20 aa at the N-terminal, two DH31-precursor-related peptides and, dibasic $\mathrm{K}_{62} \mathrm{R}$ and $\mathrm{K}_{98} \mathrm{R}$ cleavage sites, that if processed results in release of a DH31 mature peptide (Supplementary Material 4 and Figure 3F). Pt-DH31 mature peptide is homologous to N. norvegicus DH31 (Christie et al., 2009; Nguyen et al., 2018). Carcikinin has previously been identified as a crustacean orthologue of insect ecdysis triggering hormone (ETH) (Veenstra 2016). The first carcikinin has been predicted from D. pulex via transcriptomics (Gard et al., 2009). A complete carcikinin precursor comprised 136aa, with a predicted signal peptide of 19aa, followed immediately by a 16aa mature peptide. The predicted mature peptide had conserved DAGHFFAETPKHLPRIamide motif (Supplementary Material 4 and Figure 4A), which is highly conserved in other decapod species, such as $S$. paramamosain and $M$. rosenbergii (Minh Nhut et al., 2020). The putative transcript encoded a complete elevenin precursor with 147 aa. The precursor had a 27 aa predicted signal peptide, followed by a 20 aa mature peptide, and contained the conserved XXXXDCR-K/R-FVFAPXCRGIIA motif (a disulfide bridge between two cysteine residues) (Supplementary Material 4 and Figure 4B), present in other crustaceans (Christie et al., 2017; Nguyen et al., 2016).

\section{Glycoprotein-A2 (GPA2)/Glycoprotein-B5 (GPB5)/GSEFLamide (GSE)/HIGSLYRamide} and Insulin-like peptide (ILP)

A single transcript was shown to encode GPA2 precursor with 120 aa. The predicted mature peptide of 102 aa was encoded immediately after the predicted signal peptide of 18 aa

(Supplementary Material 4 and Figure 4C). These peptides share highly conserved sequence with other described decapod GPA2 isoforms, for example with $87.5 \%$ identity with amino acid sequence to C. quadricarinatus GPA2 isofrom (Nguyen et al., 2016). Pt-GPA2 mature peptide had 10 cysteine residues, possibly forming 5 disulfide bridges. Analysis of the P. trituberculatus GPA2 by DiANNA showed disulfide bridging between the first and tenth, second and eighth, third and fifth, fourth and ninth, and sixth and seventh cysteine residues of the peptide. The peptide sequence was homologous to previously reported decapod GPA2 isoforms (Christie et al., 
319 2017; Christie \& Yu 2019). The nucleotide sequence obtained from the transcriptome data had a 3202007 bp putative sequence coding for a complete GPB5 precursor with 228 aa (Supplementary

321 Material 4 and Figure 4D). The precursor had no predicted signal peptide and the mature 322 peptide had 10 cysteine residues, possibly forming 5 disulfide bridges. Analysis of this GPB5

323

324

325

326

327

328

329

330

331

332

333

334

335

336

337

338

339

340

341

342

343

344

345

346

347

348

349

350

351

352

353

354 isoform using DiANNA showed disulfide bridging between its first and tenth, second and fifth, third and fourth, sixth and eighth, and seventh and ninth cysteine residues. The isoform showed high sequence similarity to known decapod GPB5 isoforms, for example $86.51 \%$ identity in amino acid sequence to $C$. quadricarinatus GPAB5 isoform (Nguyen et al., 2016). One transcript was identified that encoded a putative GSEFLamide precursor. The precursor encodes for 358 aa, containing a 25 aa predicted signal peptide followed by 18 mature peptides flanked by multiple cleavage sites (Supplementary Material 4 and Figure 4E). The 18 predicted mature peptides were 7 to 8 aa in length and each had a conserved XGSEFLamide motif. The first putative transcript encoding HIGSLYRamide has been identified in C. maenas via in silico analyses (Christie et al., 2008). A partial precursor sequence for HIGSLYRamide was identified, comprising 758 aa and had no signal peptide (Supplementary Material 4 and Figure 4F).

Multiple dibasic KR/RR cleavage sites indicate presence of 18 mature peptides of 8 aa in length. The conserved motif of these mature peptide was H-I/L-GSL-L/Y-Ramide. A single transcript was identified to encode ILP precursor with 167 aa. The precursor had a 21 aa predicted signal peptide and 2 conserved regions( 21 aa $\mathrm{A}$ chain and 36 aa $\mathrm{B}$ chain) that formed the mature hormone (Supplementary Material 4 and Figure 5A). Pt-ILP mature peptide had 6 cysteine residues located in B chain and A chain, possibly forming 3 disulfide bridges. Analysis showed highly conserved sequence features of arthropod insulin-like peptide (Veenstra 2020).

Kinin/Myosuppressin/Neuroparsin (NP)/Neuropeptide F (NPF)and Short neuropeptide F (sNPF)

In crustaceans, the first kinin peptide was identified from Penaeus vannamei via mass spectrometry (Nieto et al., 1998). The predicted sequence of the kinin precursor was identified in the de novo assembly with no signal peptide. The precursor encodes 336 aa and has 12 predicted mature peptides, separated by multiple dibasic cleavage sites (Supplementary Material 4 and Figure 5B). In addition to the mature peptide of 13 aa, SGDSKHGRFSAWAamide, another 11 mature peptides with 6 to 7 aa in length were identified. These mature peptides had conserved XF/L-N/S-X-WAamide, e.g., QAFSAWAamide motifs, including QALNVWAamide, which are signature motifs in kinin family (Christie et al., 2010b). In decapod crustaceans, the first myosuppressin has been identified via mass spectrometry (Stemmler et al., 2007). A complete myosuppressin precursor comprised 100 aa with a predicted signal peptide of 24 aa. The precursor had two cleavage sites $\left(\mathrm{K}_{84} \mathrm{R}\right.$ and $\left.\mathrm{R}_{97}\right)$, that are processed to release the mature peptide with pQDLDHVFLRFamide sequence (Supplementary Material 4 and Figure 5C). Pt- 
355

356

357

358

359

360

361

362

363

364

365

366

367

368

369

370

371

372

373

374

375

376

377

378

379

380

381

382

383

384

385

386

387

388

389

390

myosuppressin had the same motif which is highly conserved in other known crustacean species (Christie et al., 2010b). In crustaceans, the first putative NP encoding transcripts have been predicted in C. maenas via transcripomics (Ma et al., 2009a). Three transcripts were shown to putatively encode complete NP precursors with 102 to 110 aa. All of the precursors had a predicted signal peptide of 25 to 28 aa, followed immediately by 74 to 85 aa mature peptides(Supplementary Material 4 and Figure 5D). These mature peptides had 12 conserved cysteine residues, possibly forming 6 disulfide bridges, one of which is similar to peptides reported previously in other decapod species (Ma et al., 2010; Veenstra 2016).In crustaceans, the first putative transcripts encoding NPF have been predicted in C. maenas via transcriptomics (Christie et al., 2008). Two transcripts were identified to encode 102 aa (NPF1) and 131 aa (NPF2) peptide precursors. The two precursors had predicted signal peptide of 20 aa and 26 aa, respectively (Supplementary Material 4 and Figure 5E). The predicted 67 aa (NPF1) and 70 aa (NPF2) mature peptide are encoded immediately after the signal peptide and both have the conserved RPRFamide motif, a signature motif in NPF family (Christie et al., 2010b). The first sNPF was identified from M. rosenbergii (Sithigorngul et al., 1998). A transcript of sNPF precursor was identified from the transcriptome data. The precursor encodes 126 aa, containing a 25 aa predicted signal peptide, followed by three dibasic cleavage sites that when processed results in release of three mature sNPF peptides (Supplementary Material 4 and Figure 5F). The mature peptides were 9 to 12 aa in length and had conserved PXXRLRFamide motifs, including KDARTPALRLRFamide and APPSMRLRFamide which are signature motifs of SNPF family (Christie et al., 2010b).

\section{Vasopressin/Orcokinin/Pigment-dispersing hormone (PDH)/Proctolin and Pyrokinin}

The vasopressin was first predicted from D. pulex (Stafflinger et al., 2008). A single transcript encoded a complete vasopressin-neurophysin precursor with 158 aa. The precursor comprised a 20 aa signal peptide and a dibasic cleavage site at $\mathrm{K}_{31} \mathrm{R}$ that, if processed, is predicted to release a vasopressin mature peptide and a neurophysin mature peptide (Supplementary Material 4 and Figure 6A). Pt-vasopressin mature peptide had a conserved CFITNCPPGamide motif (with a disulfide bridge between two cysteine residues). This motif has been reported in other decapod species, such as Portunus pelagicus (Saetan et al., 2018) and S. paramamosain (Lin et al., 2020). A mature 126 aa peptide with fourteen cysteine residues, probably forming seven disulfide bridges, which is characteristic of neurophysin family was identified (Bao et al., 2020). The first orcokinin peptide has been identified from C. maenas via enzyme immunoassay (Bungart et al., 1995). The putative transcript encoded a complete orcokinin precursor with 181 aa. The precursor had a predicted signal peptide with 21 aa and multiple cleavage sites that potentially results in releasing of 8 mature peptides (Supplementary Material 4 and Figure 6B). Seven peptides shared a conserved C-terminus: NFDEIDRSXFGFX 
391 motif with other known crustacean species orcokinins. Another mature peptide (named 392 orcokinin-1) had a FDAFTTGFGHS motif, which was identified as decapod orcomyotropin 393 isoform (Christie et al., 2010b). In crustaceans, the first PDH has been identified from the 394 eyestalk ganglia of Pandalus borealis (Fernlund 1976). Two PDH precursors were predicted 395 from the central nervous system transcriptome of $P$. trituberculatus, including Pt-PDH-1 and Pt396 PDH-2. These precursors encode 79 aa (PDH-1) and 78 aa (PDH-2) peptides, respectively 397 (Supplementary Material 4 and Figure 6C). The two precursors had a 22 aa signal peptide,

398

399

400

401

402

403

404

405

406

407

408

409

410

411

412

413

414

415

416

417

418

419

420

421

422

423

424

425 followed by a dibasic KR and RR cleavage site that is processed to release a mature 18 aa peptide. The two mature peptides exhibited highly conserved sequences reported in PDH of other known crustacean species (Bao et al., 2015; Christie et al., 2010b; Oliphant et al., 2018). The first proctolin-like peptide has been isolated from pericardial organs in Cardisoma carnifex (Sullivan 1979). Recently, the first putative proctolin-encoding transcript was identified from $L$. vannamei via transcriptomics (Ma et al., 2010). One proctolin precursor 94 aa in length was identified. The precursor had a 23 aa signal peptide followed immediately by the predicted mature peptide (Supplementary Material 4 and Figure 6D). Pt-Proctolin had a conserved RYLPT motif, completely conserved in other crustacean species (Christie et al., 2010b; Li et al., 2003). In decapods, pyrokinin has been first isolated and identified from $P$. vannamei (Torfs et al., 2001). A pyrokinin transcript was identified that encoded a 338 aa precursor. The precursor encoded a predicted 30 aa signal peptide and 10 mature peptides of 7 to 12 aa flanked by multiple dibasic cleavage sites (Supplementary Material 4 and Figure 6E). These mature peptides had conserved F-A/S-PR-P/Lamide motif, such as FAPRPamide, FSPRLamide, which were similar to the 5aa conserved in the C-terminal region, and FXPRLamide, which is a signature motif in pyrokinin family (Choi et al., 2012).

\section{Red pigment-concentrating hormone (RPCH)/RYamide/SIFamide/Sulfakinin} (SK)/Tachykinin (TK)/Trissin and Natalisin

The first RPCH has been purified and chemical structural has also been identified from Leander adspersus (Carlsen et al., 1976). A complete RPCH precursor was predicted from the central nervous system transcriptome. The precursor encoded 110 aa, containing a predicted 25 aa signal peptide, followed immediately by a 9 aa mature peptide and a dibasic cleavage site at $\mathrm{K}_{35} \mathrm{R}$ (Supplementary Material 4 and Figure 6F). The mature peptide had a conversed pQLNFSPGWamide motif, which is highly conserved in RPCH of other crustacean species, such as $S$. paramamosain (Zeng et al., 2016) and L. vannamei (Chen et al., 2018). The first RYamide has been identified from Cancer borealis via mass spectrometry ( $\mathrm{Li}$ et al., 2003). To date, nothing is known about the bioactivity of this peptide in crustaceans. A single transcript encoding RYamide precursor was identified from the transcriptome data. The precursor encoded 
426134 aa, including a predicted 25 aa signal peptide and multiple dibasic cleavage sites that when 427 cleaved results in release of three different mature peptides (Supplementary Material 4 and 428 Figure 7A). These mature peptides share conserved "RYamide" motif, with the sequence 429 FYSQRYamide, which is a RYamide family signature (Christie et al., 2010b). The first 430 SIFamide has been identified from P. monodon via RP-HPLC (Sithigorngul et al., 2002). One 431 transcript was identified to encode a complete SIFamide precursor with 78 aa. The precursor had 432 a predicted 27 aa signal peptide followed immediately by the mature peptide with a C-terminal 433 dibasic cleavage site $\left(\mathrm{K}_{41} \mathrm{R}\right)$ (Supplementary Material 4 and Figure 7B). The mature peptide

434

435 436 had a conversed GYRKPPFNGSIFamide motif, which showed significant similarity with other known crustacean SIFamide motifs (Christie et al., 2010b). In crustaceans, the first sulfakinins have been isolated and identified from P. monodon (Johnsen et al., 2000). The putative transcript encoded a complete sulfakinin precursor with 165 aa. The precursor had a 31 aa predicted signal peptide, followed by three dibasic cleavage sites that when processed may result in release of two mature sulfakinin peptides (Supplementary Material 4 and Figure 7C). The mature peptides, included EFDDYGHMRFamide and GSASDDYQDDYGHLRFamide, and had a Cterminal conserved DYGH-M/L-RFamide motif, which is a sulfakinin family signature (Christie et al., 2010b). The first crustacean tachykinin peptide have been identified from C. borealis (Christie et al.,1997). A single transcript was identified that encoded tachykinin precursor. The precursor encoded 226 aa, containing a 20 aa signal peptide, followed by 6 TK mature peptides each 9 aa long, and each mature peptide was flanked by cleavage sites (Supplementary Material 4 and Figure 7D). All 6 TK peptides shared the conserved XPSGFLGMRamide motif, a signature motif in other crustacean species TK peptides (Christie et al., 2010b). A complete trissin precursor transcript 201 aa long was identified. The precursor encoded a predicted signal peptide of 24 aa, followed immediately by a 29 aa mature peptide (Supplementary Material 4 and Fig 7E). The predicted trissin peptide had a conserved STVSCDSCGPECQTACGTKNFRACCFNFL motif with six cysteine residues, possibly forming three disulfide bridges. Disulfide bridges were predicted using DiANNA between the first and sixth, second and fourth, and third and fifth cysteine residues. This characteristic motif of Pt-trissin has been reported previously in other crustacean species, such as $H$. americanus (Christie et al., 2017), P. clarkia (Veenstra 2015) and other transcriptomes with trissin annotated (Bao et al., 2020; Veenstra 2016). The nucleotide sequence produced from the transcriptome data showed a 1521 bp putative coding for a complete WXXXRamide precursor with 375 aa. The precursor comprised a predicted signal peptide of 20 aa and multiple dibasic cleavage sites that results in release of 12 mature WXXXRamide peptides with 8 to 17 aa (Supplementary Material 4 and Figure 7F). These mature peptides had a conserved $\mathrm{WXXX}_{\mathrm{n}} \mathrm{Ramide}$ (where $\mathrm{Xn}$ represents a glycine or nothing) motif. 
462

463

464

465

466

467

468

469

470

471

472

473

474

475

476

477

478

479

480

481

482

483

484

485

486

487

488

489

490

491

492

493

494

495

496

497

\section{Lost neuropeptide transcripts in the CNS transcriptome of $\boldsymbol{P}$. trituberculatus.}

Notably, no transcripts encoding putative allatotropin, EH, and FLRFamide precursors were identified from the $P$. trituberculatus transcriptome. Allatotropin (AT) neuropeptide is a ubiquitous bioactive molecule that stimulates juvenile hormone production by corpora allata in insects (Bednár et al., 2017; Elekonich et al., 2003). Currently, no studies have explored on juvenile hormone in crustacean species. In addition, no study has reported AT receptor in $P$. trituberculatus transcriptome. Lack of identification of an AT signaling system in $P$. trituberculatus implies that this peptide group has been lost during evolution in decapod crustaceans (Bao et al., 2015; Christie et al., 2016; Christie et al., 2020; Christie et al., 2017; Christie \& Yu 2019; Fu et al., 2005; Nguyen et al., 2018; Veenstra 2016). EH was originally identified as a brain-derived hormone that is synthesized in ventromedial disposition in the brains of most insects (Horodyski et al., 1989). This peptide might play a role in regulation of ecdysis, a common physiological process in insects (Scott et al., 2020). Identification of EH precursors in other members of the Portunidae, such as $S$. paramamosain (Bao et al., 2015)and $S$. olivacea (Christie 2016b), implies that these signaling systems are likely to be present in $P$. trituberculatus. A putative EH transcript was identified in the testis transcriptome database of $P$. trituberculatus (Supplementary Material 7). In insects, FLRFamide is reported in endocrine and paracrine cells of the midgut (Kingan et al., 1997), however, only a few decapod crustacean species have been reported to harbor these peptides in CNS (Bao et al., 2015; Liu et al., 2019c). Analysis showed that the peptides were expressed in different tissue among diverse species. Therefore, FLRFamide expression in CNS might not have been similar as that in $S$. paramamosain. Differences in expressions may explain the absence of this neuropeptide in the transcriptome of $P$. trituberculatus. Therefore, studies should analyze midgut RNA-seq data to explore expression of this neuropeptide.

\section{Neuropeptide GPCRs prediction}

A total of 47 candidate neuropeptide GPCR transcripts were predicted from $P$. trituberculatus. In order to identify orthologs for these GPCRs, deorphanized neuropeptide GPCRs from crustaceans and insects were collected as main reference sequences. Analysis of the phylogenetic tree of these GPCRs, 39 belonged to the A-family (Figure 8), and 8 belonged to the B-family (Figure 9). However, the receptors for insulin-like peptides (ILPs) and neuroparsin (NP) are not GPCRs (Brogiolo et al., 2001; Vogel et al., 2015). In addition, the receptors for $\mathrm{CFSH}$ and orcokinin have not been currently identified in crustaceans.

\section{A-family GPCRs}

In $P$. trituberculatus, 39 A-family neuropeptide GPCRs were identified. It is relatively small putative A-family GPCR transcripts in the swimming carb compare with those identified in other related crustaceans (Bao et al., 2015; Johnson et al., 2021). This could be explained as the 
498

499

500

501

502

503

504

505

506

507

508

509

510

511

512

513

514

515

516

517

518

519

520

521

522

523

524

525

526

527

528

529

530

531

following reasoning: (1) due to low expression levels and relatively small amounts of RNAseq reads, it is extremely difficult to be identified; (2) different expression in various tissues. It is far from to identify amount of GPCR transcripts only using CNS transcriptome database. More tissues transcriptome are needed to identified more GPCR transcripts; (3) deeper sequencing is required to identify more GPCR transcripts, which have been reported in other Portunidae species. Analysis of the phylogenetic tree of A-family GPCRs showed that 32 Pt-GPCR-A sequences clustered with the known GPCR orthologs (Figure 8). The class A family comprises AST-AR, AST-BR, AST-CR, Burscion receptor, CCAPR, Corazonin receptor, ETHR, FMRFamide receptor, Moody receptor, proctolin receptor, SIFamide receptor, GPA2/GPB5receptor, CCHamide receptor, NPFR, RYamide receptor, sNPFR, RYamidereceptor, myosuppressin receptor, pyrokinin receptor, natalisin receptor, tachykinin receptor, and Vasopressin receptor. The corresponding neuropeptides of all these receptors were identified, except for FMRFamide receptor and Moody receptor which were present in $P$. trituberculatus. Similar findings were observed for S. paramamosain (Bao et al., 2015). These two species had FMRFamide receptor and Moody receptor, however their corresponding neuropeptides were not identified. This may be attributed to use of bioinformatics methods to predict neuropeptide GPCR and expression profiles which may not be sufficient. Therefore, the complete ORF sequences of these Pt-GPCRs should be cloned for accurate identification. Notably, a few neuropeptides were not identified in the receptors in this study, such as trissin receptor, RPCH receptor and ACP receptor. This can be attributed the process of filtering out of the sequences resulting in loss of short protein sequences (<150aa). Therefore, further sequencing or High-Quality Genome Assembly is required to identify trissin receptor, RPCH receptor and ACP receptor in P. trituberculatus. The identification and characterization of the $\mathrm{CHH} / \mathrm{MIH}$ receptor has remained elusive, but it is assumed that the receptors for the $\mathrm{CHH}$ family are GPCRs. In the silk moth Bombyx mori, two putative GPCRs identified BNGR-A2 and A34 as ITP receptors, and BNGR-A24 is an ITP-like receptor (member of CHHR family) (Nagai et al., 2014). Based on this discovery, Veenstra identified three transcripts as putative CHH-like receptors (CHHRs) in P. clarkia (Veenstra 2015). Subsequently, CHHR orthologs have been identified in more than ten other decapod crustacean species (Buckley et al., 2016; Johnson et al., 2021; Oliphant et al., 2018; Tran et al., 2019). One putative GPCR (Pt-GPCR-A32) was identified as $\mathrm{CHH}-$ like receptor, as this sequences clustered into the ITP receptor clade (Figure

8). In addition, a membrane guanylyl cyclase (GC- II ) is considered as the receptor activated by $\mathrm{MIH}$, resulting in immediate increase of the intracellular messenger cGMP level (Kim et al., 2004; Lee et al., 2007). Therefore, conclusive identification of the $\mathrm{CHH} / \mathrm{MIH}$ receptor awaits a 
532 functional assay that shows $\mathrm{CHH} / \mathrm{MIH}$ activation of their putative receptor expressed in a 533 heterologous reporting system (Aizen et al., 2016; Ventura et al., 2017).

534

535

536

537

538

539

540

541

542

543

544

545

546

547

548

549

550

551

552

553

554

555

556

557

558

559

560

561

562

563

564

565

566

567

\section{Leucine-rich repeat-containing GPCRs (LGRs)}

As a member of rhodopsin-like GPCR family, three distinct types of LGRs have been classified (A-C) based on the number of leucine-rich repeat (LRR)motifs, low density lipoprotein (LDL) motifs and hinge region sequence(Van Hiel et al., 2012). Four putative LGRs were identified in the phylogenetic analysis (Figure 8). Pt-GPCR-A11 and Pt-GPCR-A14 clustered with the burscion receptor (type B LGR2) and Pt-GPCR-A16 clustered with GPA2/GPB5 receptor (type A LGR1). LGR2 serves as the receptor for burscion, which regulates molting of the cuticle in C. maenas (Webster et al., 2013; Wilcockson \& Webster 2008) and reproduction and ovarian development in female shrimp, P. monodon (Sathapondecha et al., 2015). In D.melanogaster, GPA2 and GPB5 function via DLGR1 (Hsueh et al., 2005), which has been reported to play a critical role in development (Vandersmissen et al., 2014). The function of LGR1 remains a little obscure in crustacean species. Another LGR identified (Pt-GPCR-A33) clustered with relaxin receptor (LGR4,type C1 LGR). Recent experimental evidence from $D$. melanogaster suggests LGR4 activated by dilp7, which has also been called relaxin (Imambocus et al., 2020). In insects, relaxin influences lipid synthesis and regulates egg laying decisions (Semaniuk et al., 2018; Yang et al., 2008). In 2020, Vennstra (Veenstra 2020) has been reported relaxin and LGR4 in eight decapod species. It might suggest that relaxin may be LGR4 ligand. Furthermore, ligand-receptor binding tests are needed to verify this hypothesis. However, the physiological function of relaxin in crustaceans remains unclear.

\section{Orphan rhodopsin-like GPCRs}

Orphan receptors are predicted to be involved in neuropeptide signaling pathways, but the ligands and function are still unknown. Since seven Drosophila orphan receptors were identified, orphan receptors orthologs have been identified in crustaceans subsequently (Bao et al., 2020; Caers et al., 2012; Johnson et al., 2021). Two putative GPCRs (Pt-GPCR-A12 and Pt-GPCRA13) clustered with the Moody receptor ortholog and Pt-GPCR-A27 clustered with Tre receptor ortholog. In P. argus, Moody receptors might be indirectly involved in chemical sensing (Kozma et al., 2020). Little is known about Tre receptor phylogeny or function in crustaceans. In D. melanogaster, Tre receptor might have been involved in chemical sensing and in regulating male courtship behavior (Luu et al., 2016). Much experimental evidence are needed to investigate the similar function of Tre receptor in decapod species as those in insects.

\section{Other GPCRs of interest}

Two alternatively splices ETHRs (ETHR-A and ETHR-B) are encoded by ethr gene and expressed in discrete central neurons that are thought to be differently involved in pre-ecdysis and ecdysis (Diao et al., 2016; Kim et al., 2006; Žitňan et al., 2007). Pt-GPCR-A6 clustered with 
568 ETHR-B ortholog. In crustacean, numerous reports show ETHR transcripts in the CNS, but 569 information on the role of these receptors in molting is still unclear (Minh Nhut et al., 2020). Crz, 570 a paralog of gonadotropin-releasing hormone, has various functions in different insects, such as 571 affecting ecdysis in Manduca sexta (Žitňan et al., 2007), participating in the pigmentation 572 process in locusts (Tawfik et al., 1999) and increasing heart activity in Periplaneta Americana 573 (Veenstra 1989). However, Crz has no effect on heart activity, blood glucose level, lipid 574 mobilization or pigment distribution in C. maenas (Alexander et al., 2018). Although CrzR is 575 highly expressed in the YO, but it has little effect on ecdysteroid biosynthesis except a slightly 576 stimulation in early postmolt (Alexander et al., 2018; Tran et al., 2019). In addition, Pt-GPCR577 A3 clustered with CrzR ortholog. Crz and CrzR have been identified as an orthologue of GnRH 578 and GnRHR in vertebrates, respectively. GnRH has been involved in regulation of reproductive 579 processes in vertebrates. Still, whether Crz/CrzR signaling pathways in crustaceans plays a role 580 in reproduction requires further investigation. Based on two conserved cysteines and an amidated 581 histidine residue at the $\mathrm{C}$ terminus, this peptide has been called CCHamide, which is an 582 invertebrate neuropeptide (Roller et al., 2008). In D. melanogaster, CCHamide-2 binds 583 CHHamide-2 receptor to affect feeding behavior (Nitabach et al., 2013). In Gecarcinus lateralis, 584 two putative CCHamide receptors expressed great differences in all four molt stages and its 585 suggest that these receptors might be play an important role in molting (Tran et al., 2019). In 586 addition, no studies reported CCHamide and their receptors related to reproduction in

587 588 589 590

591

592

593

594

595

596

597

598

599

600 601 602 crustaceans. The role of CCHamide and their receptors in reproduction is still vague.

\section{B-family GPCRs}

A total of 8 predicted GPCRs clustered with Secretin-like receptors (class B) (Figure 9). PDFR, DH31R, and DH44R are members of B-family GPCRs in insects (Cardoso et al., 2014), and all these B-family GPCRs were identified in P. trituberculatus. Pt-GPCR-B1 and Pt-GPCRB2 clustered with the Calcitonin receptor ortholog. Pt-GPCR-B3, Pt-GPCR-B7 and Pt-GPCR-B8 clustered with PDF receptor ortholog. Pt-GPCR-B4 clustered with DH31 receptor ortholog. PtGPCR-B5 clustered with the DH44 receptor ortholog. Pt-GPCR-B6 clustered with the PTH-like receptor ortholog. Notably, three putative PDFRs (Pt-GPCR-B3, Pt-GPCR-B7, and Pt-GPCRB8) were identified in P. trituberculatus. Also, three putative PDFRs (PDHRs) have been identified in C. maenas (Oliphant et al., 2018). Subsequently, only two of these putative receptors turned out to be functional by ligand-receptor binding tests (Alexander et al., 2020). In addition, Pt-GPCR-B3 is not a complete ORF and that may lead to an inaccurate cluster. Therefore, a complete ORF of Pt-GPCR-B3 should be cloned for reliable identification. 
603

604

605

606

607

608

609

610

611

612

613

614

615

616

617

618

619

620

621

622

623

624

625

626

627

628

629

630

631

632

633

634

635

636

637

638

After obtaining nucleotide sequences of $P$. trituberculatus neuropeptide, their expression was explored in different tissues using RT-PCR to confirm that neuropeptide transcripts were synthesized in the CNS, and/or ovary; and check whether these transcripts were expressed in other tissues. A total of 32 putative neuropeptide-encoding transcripts of interest were detected in various tissues (Figure 10). RT-PCR results showed that all of the 32 neuropeptide transcripts were present in CNS, mainly in cerebral ganglia, eyestalk ganglia, and ventral ganglia, which is consistent with their roles as neuropeptides. This finding showed that the predicted neuropeptides sequences, obtained from $P$. trituberculatus CNS transcriptome databases are reliable. Moreover, twenty-three neuropeptide transcripts, including ACP, ALP, AST-B, AST-CCC, CCAP, CHH1, CHH2, CNM, Elevenin, GPA2, GPB5, GSE, Kinin, Myosuppressin, NP1, NP2, NP3, sNPF, PDH1, PDH2, RYamide, Tachykinin, and Trissin were expressed in the ovary. This suggests that the putative neuropeptide might be involved in ovarian development and ovarian maturation.

A total of 33 neuropeptide GPCR transcripts (27 were Pt-GPCR-As and 6 belonged to PtGPCR-Bs) were chosen for assessment of their tissue distribution of female P. trituberculatus (Figure 11). Most of these neuropeptide GPCRs were expressed in various tissues as well as neuropeptides. Notably, most of the GPCRs found in the ovary were similar to the expression profiles of neuropeptides. This might suggest that neuropeptide/GPCR signaling pathways are involved in regulation of the ovarian cycle. Five GPCRs, including CCAPR, FMRFamide receptor, Proctolin receptor, AST-BR, and PDFRs, were expressed in ovary, and showed similar expression profiles to those in $S$. paramamosain (Bao et al., 2018b). Other GPCRs expression profiles in P. trituberculatus did not show corresponding GPCRs in S. paramamosain. This might be because the GPCRs selected for assessment of tissue expression were different from those in S. paramamosain. In addition, some unknown GPCRs were detected in the ovaries of two species. Therefore, further studies should explore expression of these transcripts among various species. Pt-GPCR-A9, was highly expressed in gill, but this sequences clustered with the unknown GPCR orthologs. Pt-GPCR-A4 (CCAPR), Pt-GPCR-A27 (FMRFamide receptor)and Pt-GPCR-B6 (PTH-like receptor) were significantly expressed in ovary, compared with the levels in other tissues. Pt-GPCR-A33 (relaxin receptor) was only expressed in CNS and ovary. These results suggest that CCAPR, FMRFamide receptor, PTH-like receptor and relaxin receptor might be related to ovarian development. Further gene expression analysis should be designed to examine the expression of these GPCRs throughout development and in response to processes such as ovarian development and reproductive maturation.

In summary, several neuropeptide/GPCR signaling pathways have been reported in $P$. trituberculatus as well as other decapod species and in insects. Recent studies report that several neuropeptide/GPCR signaling pathways are involved in crustacean reproduction. These include AST-C/putative AST-CR (Liu et al., 2019a), sNPF/sNPFR (Bao et al. 2018a), and 
639 Vasopressin/putative vasopressin receptor (Lin et al., 2020). These signaling pathways were also 640 identified in P. trituberculatus, however information on the function of these pathways is still 641 unclear. Therefore, further studies are required to gain a better understanding of the function of 642 these neuropeptide/GPCR signaling pathways on the reproduction system of decapod crustacean 643 species.

644

\section{Conclusion}

646 In the present study, 47 neuropeptide transcripts and 47 GPCR transcripts were identified in 647 CNS transcriptome data of $P$. trituberculatus. Notably, only allatotropin, EH, and FLRFamide 648 were absent in the dataset. A total of 32 neuropeptide transcripts and 33 GPCR transcripts were 649 chosen for assessment of expression in different tissues. Analysis showed that 23 neuropeptide 650 transcripts and 20 GPCR transcripts, were expressed in the ovary implying that they might be 651 involved in regulation of reproduction. Moreover, most of these neuropeptide/GPCR signaling 652 pathways have been reported in P. trituberculatus as well as other decapod species or insects, 653 implying that they may play similar function in other species. Further, studies should explore the 654 functions of these neuropeptides. In summary, the findings of this study provide a reference for 655 exploring neuropeptide/GPCR distribution in other decapod species. In addition, these findings provide a basis for further studies on neuropeptidergic control of the physiology and behavior of decapod crustaceans.

658

659

660

661

662

663

664

665

666

667

668

669

670

671

672

\section{References}

Aizen J, Chandler JC, Fitzgibbon QP, Sagi A, Battaglene SC, Elizur A, and Ventura T. 2016. Production of recombinant insulin-like androgenic gland hormones from three decapod species: In vitro testicular phosphorylation and activation of a newly identified tyrosine kinase receptor from the Eastern spiny lobster, Sagmariasus verreauxi. General and Comparative Endocrinology 229:8-18. 10.1016/j.ygcen.2016.02.013

Alexander JL, Oliphant A, Wilcockson DC, Audsley N, Down RE, Lafont R, and Webster SG. 2018. Functional Characterization and Signaling Systems of Corazonin and Red Pigment Concentrating Hormone in the Green Shore Crab, Carcinus maenas. Frontiers in Neuroscience 11:752. 10.3389/fnins.2017.00752

Alexander JL, Oliphant A, Wilcockson DC, Brendler-Spaeth T, Dircksen H, and Webster SG. 2020. Pigment Dispersing Factors and Their Cognate Receptors in a Crustacean Model, With New Insights Into Distinct Neurons and Their Functions. Frontiers in Neuroscience 14:595648. 10.3389/fnins.2020.595648 
673 Bao C, Liu F, Yang Y, Lin Q, and Ye H. 2020. Identification of Peptides and Their GPCRs in

674

675

676

677

678

679

680

681

682

683

684

685

686

687

688

689

690

691

692

693

694

695

696

697

698

699

700

701

702

703

704

705

706

707

708

709

710

711

712

713 the Peppermint Shrimp Lysmata vittata, a Protandric Simultaneous Hermaphrodite Species. Frontiers in Endocrinology 11:226. 10.3389/fendo.2020.00226

Bao C, Yang Y, Huang H, and Ye H. 2015. Neuropeptides in the cerebral ganglia of the mud crab, Scylla paramamosain: transcriptomic analysis and expression profiles during vitellogenesis. Scientific Reports 5:17055. 10.1038/srep17055

Bao C, Yang Y, Huang H, and Ye H. 2018a. Inhibitory Role of the Mud Crab Short Neuropeptide F in Vitellogenesis and Oocyte Maturation via Autocrine/Paracrine Signaling. Frontiers in Endocrinology 9:390. 10.3389/fendo.2018.00390

Bao C, Yang Y, Zeng C, Huang H, and Ye H. 2018b. Identifying neuropeptide GPCRs in the mud crab, Scylla paramamosain, by combinatorial bioinformatics analysis. General and Comparative Endocrinology 269:122-130. 10.1016/j.ygcen.2018.09.002

Bednár B, Roller L, Čižmár D, Mitrová D, and Žitňan D. 2017. Developmental and sex-specific differences in expression of neuropeptides derived from allatotropin gene in the silkmoth Bombyx mori. Cell and Tissue Research 368:259-275. 10.1007/s00441-016-2556-X

Brody T, and Cravchik A. 2000. Drosophila melanogaster G protein-coupled receptors. Journal of Cell Biology 150:F83-88. 10.1083/jcb.150.2.f83

Brogiolo W, Stocker H, Ikeya T, Rintelen F, Fernandez R, and Hafen E. 2001. An evolutionarily conserved function of the Drosophila insulin receptor and insulin-like peptides in growth control. Current Biology 11:213-221. Doi 10.1016/S0960-9822(01)00068-9

Buckley SJ, Fitzgibbon QP, Smith GG, and Ventura T. 2016. In silico prediction of the G-protein coupled receptors expressed during the metamorphic molt of Sagmariasus verreauxi (Crustacea: Decapoda) by mining transcriptomic data: RNA-seq to repertoire. General and Comparative Endocrinology 228:111-127. 10.1016/j.ygcen.2016.02.001

Bungart D, Hilbich C, Dircksen H, and Keller R. 1995. Occurrence of Analogs of the Myotropic Neuropeptide Orcokinin in the Shore Crab, Carcinus maenas : Evidence for a Novel Neuropeptide Family. Peptides 16:67-72. Doi 10.1016/0196-9781(94)00145-V

Buratti E, Manfrin C, Tom M, De Moro G, Gerdol M, Guarnaccia C, Mosco A, Pallavicini A, and Giulianini PG. 2013. Application of D-Crustacean Hyperglycemic Hormone Induces Peptidases Transcription and Suppresses Glycolysis-Related Transcripts in the Hepatopancreas of the Crayfish Pontastacus leptodactylus - Results of a Transcriptomic Study. Plos One 8:e65176. 10.1371/journal.pone.0065176

Caers J, Verlinden H, Zels S, Vandersmissen HP, Vuerinckx K, and Schoofs L. 2012. More than two decades of research on insect neuropeptide GPCRs: an overview. Frontiers in Endocrinology 3:151. 10.3389/fendo.2012.00151

Cardoso JC, Felix RC, and Power DM. 2014. Nematode and arthropod genomes provide new insights into the evolution of class 2 B1 GPCRs. Plos One 9:e92220. 10.1371/journal.pone.0092220

Carlsen J M CM, Josefsson L. 1976. Purification and chemical structure of the red pigmentconcentrating hormone of the prawn Leander adspersus. General and Comparative Endocrinology 30:327-331. 10.1016/0016-6480(76)90083-6 
714 Chen H Y, Kang BJ, Sultana Z, and Wilder MN. 2018. Molecular cloning of red pigment-

715

716

717

718

719

720

721

722

723

724

725

726

727

728

729

730

731

732

733

734

735

736

737

738

739

740

741

742

743

744

745

746

747

748

749

750

751

752

753 concentrating hormone $(\mathrm{RPCH})$ from eyestalks of the whiteleg shrimp (Litopenaeus vannamei): Evaluation of the effects of the hormone on ovarian growth and the influence of serotonin (5-HT) on its expression. Aquaculture 495:232-240. 10.1016/j.aquaculture.2018.04.027

Choi CY, Zheng J, and Watson RD. 2006. Molecular cloning of a cDNA encoding a crustacean hyperglycemic hormone from eyestalk ganglia of the blue crab, Callinectes sapidus. General and Comparative Endocrinology 148:383-387. 10.1016/j.ygcen.2006.03.003

Choi M Y, and Vander Meer RK. 2012. Molecular Structure and Diversity of PBAN/pyrokinin Family Peptides in Ants. Frontiers in Endocrinology 3:32. 10.3389/fendo.2012.00032

Christie A E, Lundquist CT, Nässel D R, Nusbaum M P 1997. Two novel tachykinin-related peptides from the nervous system of the crab Cancer borealis. The Journal of Experimental Biology Pt 17:2279-2294. PMID 9316266

Christie AE. 2014. Expansion of the Litopenaeus vannamei and Penaeus monodon peptidomes using transcriptome shotgun assembly sequence data. General and Comparative Endocrinology 206:235-254. 10.1016/j.ygcen.2014.04.015

Christie AE. 2016a. Expansion of the neuropeptidome of the globally invasive marine crab Carcinus maenas. General and Comparative Endocrinology 235:150-169. 10.1016/j.ygcen.2016.05.013

Christie AE. 2016b. Prediction of Scylla olivacea (Crustacea; Brachyura) peptide hormones using publicly accessible transcriptome shotgun assembly (TSA) sequences. General and Comparative Endocrinology 230-231:1-16. 10.1016/j.ygcen.2016.03.008

Christie AE. 2020. Identification of putative neuropeptidergic signaling systems in the spiny lobster, Panulirus argus. Invertebrate Neuroscience 20:1-12. 10.1007/s10158-020-0235-9

Christie AE, Cashman CR, Brennan HR, Ma M, Sousa GL, Li L, Stemmler EA, and Dickinson PS. 2008. Identification of putative crustacean neuropeptides using in silico analyses of publicly accessible expressed sequence tags. General and Comparative Endocrinology 156:246-264. 10.1016/j.ygcen.2008.01.018

Christie AE, and Chi M. 2015. Prediction of the neuropeptidomes of members of the Astacidea (Crustacea, Decapoda) using publicly accessible transcriptome shotgun assembly (TSA) sequence data. General and Comparative Endocrinology 224:38-60. 10.1016/j.ygcen.2015.06.001

Christie AE, Durkin CS, Hartline N, Ohno P, and Lenz PH. 2010a. Bioinformatic analyses of the publicly accessible crustacean expressed sequence tags (ESTs) reveal numerous novel neuropeptide-encoding precursor proteins, including ones from members of several little studied taxa. General and Comparative Endocrinology 167:164-178. 10.1016/j.ygcen.2010.01.005

Christie AE, and Pascual MG. 2016. Peptidergic signaling in the crab Cancer borealis: Tapping the power of transcriptomics for neuropeptidome expansion. General and Comparative Endocrinology 237:53-67. 10.1016/j.ygcen.2016.08.002

PeerJ reviewing PDF | (2021:05:61499:1:2:NEW 17 Aug 2021) 
754 Christie AE, Rivera CD, Call CM, Dickinson PS, Stemmler EA, and Hull JJ. 2020. Multiple

755

756

757

758

759

760

761

762

763

764

765

766

767

768

769

770

771

772

773

774

775

776

777

778

779

780

781

782

783

784

785

786

787

788

789

790

791

792

793 transcriptome mining coupled with tissue specific molecular cloning and mass spectrometry provide insights into agatoxin-like peptide conservation in decapod crustaceans. General and Comparative Endocrinology 299:113609.

10.1016/j.ygcen.2020.113609

Christie AE, Roncalli V, Cieslak MC, Pascual MG, Yu A, Lameyer TJ, Stanhope ME, and Dickinson PS. 2017. Prediction of a neuropeptidome for the eyestalk ganglia of the lobster Homarus americanus using a tissue-specific de novo assembled transcriptome. General and Comparative Endocrinology 243:96-119. 10.1016/j.ygcen.2016.11.001

Christie AE, Stemmler EA, and Dickinson PS. 2010b. Crustacean neuropeptides. Cellular and Molecular Life Sciences 67:4135-4169. 10.1007/s00018-010-0482-8

Christie AE, Stevens JS, Bowers MR, Chapline MC, Jensen DA, Schegg KM, Goldwaser J, Kwiatkowski MA, Pleasant TK, Shoenfeld L, Tempest LK, Williams CR, Wiwatpanit T, Smith CM, Beale KM, Towle DW, Schooley DA, and Dickinson PS. 2009. Identification of a calcitonin-like diuretic hormone that functions as an intrinsic modulator of the American lobster, Homarus americanus, cardiac neuromuscular system. Journal of Experimental Biology 213:118-127. 10.1242/jeb.037077

Christie AE, and Yu A. 2019. Identification of peptide hormones and their cognate receptors in Jasus edwardsii - A potential resource for the development of new aquaculture management strategies for rock/spiny lobsters. Aquaculture 503:636-662. 10.1016/j.aquaculture.2018.11.059

Davies MN, Gloriam DE, Secker A, Freitas AA, Mendao M, Timmis J, and Flower DR. 2007. Proteomic applications of automated GPCR classification. Proteomics 7:2800-2814. 10.1002/pmic.200700093

Diao F MW, Shi J, Park D, Diao F, Taghert P, Ewer J, H. White B. 2016. The splice isoforms ofthe Drosophila ecdysis triggering hormone receptor have developmentallydistinct roles. Genetics 202:175-189. 10.1534/genetics.115.182121/-/DC1

Sullivan R E. 1979. A proctolin-like peptide in crab pericardial organs. Journal of Experimental Zoology 210:543-552. 10.1002/jez.1402100318

Elekonich MM, and Horodyski FM. 2003. Insect allatotropins belong to a family of structurallyrelated myoactive peptides present in several invertebrate phyla. Peptides 24:1623-1632. 10.1016/j.peptides.2003.08.011

Fu Q, Kutz KK, Schmidt JJ, Hsu Y-WA, Messinger DI, Cain SD, de la Iglesia HO, Christie AE, and Li L. 2005. Hormone complement of the Cancer productus sinus gland and pericardial organ: An anatomical and mass spectrometric investigation. The Journal of Comparative Neurology 493:607-626. 10.1002/cne.20773

Gard AL, Lenz PH, Shaw JR, and Christie AE. 2009. Identification of putative peptide paracrines/hormones in the water flea Daphnia pulex (Crustacea; Branchiopoda; Cladocera) using transcriptomics and immunohistochemistry. General and Comparative Endocrinology 160:271-287. 10.1016/j.ygcen.2008.12.014

PeerJ reviewing PDF | (2021:05:61499:1:2:NEW 17 Aug 2021) 
794 González M, Betancourt JL, Rodríguez - Ramos T, Estrada MP, Carpio Y, and Ramos L. 2020.

795

796

797

798

799

800

801

802

803

804

805

806

807

808

809

810

811

812

813

814

815

816

817

818

819

820

821

822

823

824

825

826

827

828

829

830

831

832

833

Induction of spawning in Pacific white shrimp Litopenaeus vannamei(Boone, 1931) by injection of its molt inhibiting hormone isoform II produced in E. coli. Aquaculture Research 51:3100-3108. 10.1111/are.14644

Gouy M, Guindon S, and Gascuel O. 2009. SeaView Version 4: A Multiplatform Graphical User Interface for Sequence Alignment and Phylogenetic Tree Building. Molecular Biology and Evolution 27:221-224. 10.1093/molbev/msp259

Grabherr MG, Haas BJ, Yassour M, Levin JZ, Thompson DA, Amit I, Adiconis X, Fan L, Raychowdhury R, Zeng Q, Chen Z, Mauceli E, Hacohen N, Gnirke A, Rhind N, di Palma F, Birren BW, Nusbaum C, Lindblad-Toh K, Friedman N, and Regev A. 2011. Fulllength transcriptome assembly from RNA-Seq data without a reference genome. Nature Biotechnology 29:644-652. 10.1038/nbt.1883

Horodyski FM, Riddiford LM, and Truman JW. 1989. Isolation and expression of the eclosion hormone gene from the tobacco hornworm, Manduca sexta. Proceedings of the National Academy of Sciences of the United States of America 86:8123-8127. 10.1073/pnas.86.20.8123

Hsueh AJW, Hsu SY, Park J-I, Kuwabara Y, and Sudo S. 2005. Heterodimeric Fly Glycoprotein Hormone- $\alpha 2$ (GPA2) and Glycoprotein Hormone- $\beta 5$ (GPB5) Activate Fly Leucine-Rich Repeat-Containing G Protein-Coupled Receptor-1 (DLGR1) and Stimulation of Human Thyrotropin Receptors by Chimeric Fly GPA2 and Human GPB5. Endocrinology 146:3596-3604. 10.1210/en.2005-0317

Imambocus BN, Wittich A, Tenedini F, Zhou F, Hu C, Sauter K, Varela EM, Herédia F, Casimiro AP, Macedo A, Schlegel P, Yang C-H, Miguel-Aliaga I, Pankratz MJ, Gontijo AM, Cardona A, and Soba P. 2020. Discrete escape responses are generated by neuropeptide-mediated circuit logic. bioRxiv: the preprint server for biology. $10.1101 / 2020.09 .22 .307033$

Johnsen A H, Duve H, Davey M, Hall M, Thorpe A. 2000. Sulfakinin neuropeptides in a crustacean. Isolation, identification andtissue localization in the tiger prawn Penaeus monodon. European Journal of Biochemistry 267:1153-1160. 10.1046/j.14321327.2000.01113.x

Johnson EC, Christie AE, Chi M, Lameyer TJ, Pascual MG, Shea DN, Stanhope ME, Schulz DJ, and Dickinson PS. 2015. Neuropeptidergic Signaling in the American Lobster Homarus americanus: New Insights from High-Throughput Nucleotide Sequencing. Plos One 10:e0145964.10.1371/journal.pone.0145964

Johnson EC, Rump MT, Kozma MT, Pawar SD, and Derby CD. 2021. G protein-coupled receptors as candidates for modulation and activation of the chemical senses in decapod crustaceans. Plos One 16:e0252066. 10.1371/journal.pone.0252066

Kegel G, Reichwein B, Weese S, Gaus G, Peter-Kataliníc J and Keller R. 1989. Amino acid sequence of the crustacean hyperglycemic hormone $(\mathrm{CHH})$ from the shore crab, Carcinus maenas. FEBS letters 255:10-14. 10.1016/0014-5793(89)81051-8

Peer) reviewing PDF | (2021:05:61499:1:2:NEW 17 Aug 2021) 
834 Kim H-W, Batista LA, Hoppes JL, Lee KJ, and Mykles DL. 2004. A crustacean nitric oxide

835 synthase expressed in nerve ganglia, Y-organ, gill and gonad of the tropical land

$836 \quad$ crab,Gecarcinus lateralis. Journal of Experimental Biology 207:2845-2857.

$837 \quad 10.1242 /$ jeb.01117

838 Kim YJ, Zitnan D, Cho KH, Schooley DA, Mizoguchi A, and Adams ME. 2006. Central

839 peptidergic ensembles associated with organization of an innate behavior. Proceedings of

840 the National Academy of Sciences 103:14211-14216. 10.1073/pnas.0603459103

841 Kingan TG, Zitnan D, Jaffe H, and Beckage NE. 1997. Identification of neuropeptides in the

842 midgut of parasitized insects: FLRFamides as candidate paracrines. Molecular and

843 Cellular Endocrinology 133:19-32. 10.1016/s0303-7207(97)00140-8

844 Klein JM, Mangerich, S, Kleijn, D, Keller, R, Weidemann, Weidemann. W M. 1993. Molecular

$845 \quad$ cloning of crustacean putative molt-inhibiting hormone (MIH) precursor. FEBS Letters

$846 \quad 334: 139-142.10 .1016 / 0014-5793(93) 81699-z$

847 Kozma MT, Ngo-Vu H, Rump MT, Bobkov YV, Ache BW, and Derby CD. 2020. Single cell

848 transcriptomes reveal expression patterns of chemoreceptor genes in olfactory sensory

849

850

851

852

853

854

855

856

857

858

859

860

861

862

863

864

865 neurons of the Caribbean spiny lobster, Panulirus argus. BMC Genomics 21. 10.1186/s12864-020-07034-7

Lee S G, Bader B D, Chang E S, and Mykles D L. 2007. Effects of elevated ecdysteroid on tissue expression of three guanylyl cyclases in the tropical land crab Gecarcinus lateralis: possible roles of neuropeptide signaling in the molting gland. Journal of Experimental Biology 210:3245-3254. 10.1242/jeb.007740

Li L, Kelley WP, Billimoria CP, Christie AE, Pulver SR, Sweedler JV, and Marder E. 2003. Mass spectrometric investigation of the neuropeptide complement and release in the pericardial organs of the crab, Cancer borealis. Journal of Neurochemistry 87:642-656. 10.1046/j.1471-4159.2003.02031.x

Lin D, Wei Y, and Ye H. 2020. Role of Oxytocin/Vasopressin-Like Peptide and Its Receptor in Vitellogenesis of Mud Crab. International Journal of Molecular Sciences 21:2297. 10.3390/ijms21072297

Liu A, Liu F, Shi W, Huang H, Wang G, and Ye H. 2019a. C-Type allatostatin and its putative receptor from the mud crab serve an inhibitory role in ovarian development. The Journal of Experimental Biology 222:jeb207985. 10.1242/jeb.207985

866

867

868

869

870

871

872

873

874

Liu A, Liu J, Chen X, Lu B, Zeng C, and Ye H. 2019b. A novel crustacean hyperglycemic hormone $(\mathrm{CHH})$ from the mud crab Scylla paramamosain regulating carbohydrate metabolism. Comparative Biochemistry and Physiology Part A: Molecular and Integrative Physiology 231:49-55. 10.1016/j.cbpa.2019.01.015

Liu X, Ma K, Liu Z, Feng J, Ye B, and Qiu G. 2019c. Transcriptome analysis of the brain of the Chinese mitten crab, Eriocheir sinensis, for neuropeptide abundance profiles during ovarian development. Animal Reproduction Science 201:63-70. 10.1016/j.anireprosci.2018.12.010

Luo X, Chen T, Zhong M, Jiang X, Zhang L, Ren C, and Hu C. 2015. Differential regulation of hepatopancreatic vitellogenin (VTG) gene expression by two putative molt-inhibiting 
875

876

877

878

879

880

881

882

883

884

885

886

887

888

889

890

891

892

893

894

895

896

897

898

899

900

901

902

903

904

905

906

907

908

909

910

911

912

913

914

hormones (MIH1/2) in Pacific white shrimp (Litopenaeus vannamei). Peptides 68:58-63. 10.1016/j.peptides.2014.11.002

Luu P, Zaki SA, Tran DH, and French RL. 2016. A Novel Gene Controlling the Timing of Courtship Initiation in Drosophila melanogaster. Genetics 202:1043-1053. 10.1534/genetics.115.183061

Ma M, Bors EK, Dickinson ES, Kwiatkowski MA, Sousa GL, Henry RP, Smith CM, Towle DW, Christie AE, and Li L. 2009a. Characterization of the Carcinus maenas neuropeptidome by mass spectrometry and functional genomics. General and Comparative Endocrinology 161:320-334. 10.1016/j.ygcen.2009.01.015

Ma M, Gard AL, Xiang F, Wang J, Davoodian N, Lenz PH, Malecha SR, Christie AE, and Li L. 2010. Combining in silico transcriptome mining and biological mass spectrometry for neuropeptide discovery in the Pacific white shrimp Litopenaeus vannamei. Peptides 31:27-43. 10.1016/j.peptides.2009.10.007

Ma M, Szabo TM, Jia C, Marder E, and Li L. 2009b. Mass spectrometric characterization and physiological actions of novel crustacean C-type allatostatins. Peptides 30:1660-1668. 10.1016/j.peptides.2009.05.023

Meng X, Zhang M, Gao B, Lv J, Li J, and Liu P. 2020. Integrative Proteomic and MicroRNA Analysis: Insights Into Mechanisms of Eyestalk Ablation-Induced Ovarian Maturation in the Swimming Crab Portunus trituberculatus. Frontiers in Endocrinology 11:533. 10.3389/fendo.2020.00533

Minh Nhut T, Mykles DL, Elizur A, and Ventura T. 2020. Ecdysis triggering hormone modulates molt behaviour in the redclaw crayfish Cherax quadricarinatus, providing a mechanistic evidence for conserved function in molt regulation across Pancrustacea. General and Comparative Endocrinology 298:113556. 10.1016/j.ygcen.2020.113556

Nagai C, Mabashi-Asazuma H, Nagasawa H, and Nagata S. 2014. Identification and Characterization of Receptors for Ion Transport Peptide (ITP) and ITP-like (ITPL) in the Silkworm Bombyx mori. Journal of Biological Chemistry 289:32166-32177. 10.1074/jbc.M114.590646

Nguyen TV, Cummins SF, Elizur A, and Ventura T. 2016. Transcriptomic characterization and curation of candidate neuropeptides regulating reproduction in the eyestalk ganglia of the Australian crayfish, Cherax quadricarinatus. Scientific Reports 6:38658. $10.1038 /$ srep38658

Nguyen TV, Rotllant GE, Cummins SF, Elizur A, and Ventura T. 2018. Insights Into Sexual Maturation and Reproduction in the Norway Lobster (Nephrops norvegicus) via in silico Prediction and Characterization of Neuropeptides and G Protein-coupled Receptors. Frontiers in Endocrinology 9:430. 10.3389/fendo.2018.00430

Nieto J,Veelaert D, Derua R, Waelkens E, Cerstiaens A, Coast G, Devreese B, Van B J , Calderon J, De Loof A, Schoofs L 1998. Identification of One Tachykinin- and Two Kinin-Related Peptides in the Brain of the White Shrimp,Penaeus vannamei. 
915 Nitabach Michael N, Li S, Torre-Muruzabal T, Søgaard KC, Ren GR, Hauser F, Engelsen SM, 916 Pødenphanth MD, Desjardins A, and Grimmelikhuijzen CJP. 2013. Expression Patterns

917

918

919

920

921

922

923

924

925

926

927

928

929

930

931

932

933

934

935

936

937

938

939

940

941

942

943

944

945

946

947

948

949

950

951

952

953

954

955 of the Drosophila Neuropeptide CCHamide-2 and Its Receptor May Suggest Hormonal Signaling from the Gut to the Brain. Plos One 8:e76131. 10.1371/journal.pone.0076131

Oliphant A, Alexander JL, Swain MT, Webster SG, and Wilcockson DC. 2018. Transcriptomic analysis of crustacean neuropeptide signaling during the moult cycle in the green shore crab, Carcinus maenas. BMC Genomics 19:711. 10.1186/s12864-018-5057-3

Oliphant A, Hawkes MKN, Cridge AG, and Dearden PK. 2020. Transcriptomic characterisation of neuropeptides and their putative cognate $\mathrm{G}$ protein-coupled receptors during late embryo and stage-1 juvenile development of the Aotearoa-New Zealand crayfish, Paranephrops zealandicus. General and Comparative Endocrinology 292:113443. 10.1016/j.ygcen.2020.113443

Fernlund P. 1976. Structure of a light-adapting hormone from the shrimp, Pandalus borealis. Biochimica Et Biophysica Acta 439:17-25. 10.1016/0005-2795(76)90155-0

Ren J, Wen L, Gao X, Jin C, Xue Y, and Yao X. 2009. DOG 1.0: illustrator of protein domain structures. Cell Research 19:271-273. 10.1038/cr.2009.6

Roller L, Yamanaka N, Watanabe K, Daubnerová I, Žitňan D, Kataoka H, and Tanaka Y. 2008. The unique evolution of neuropeptide genes in the silkworm Bombyx mori. Insect Biochemistry and Molecular Biology 38:1147-1157. 10.1016/j.ibmb.2008.04.009

Saetan J, Kruangkum T, Phanthong P, Tipbunjong C, Udomuksorn W, Sobhon P, and Sretarugsa P. 2018. Molecular cloning and distribution of oxytocin/vasopressin-like mRNA in the blue swimming crab, Portunus pelagicus, and its inhibitory effect on ovarian steroid release. Comparative Biochemistry and Physiology Part A: Molecular and Integrative Physiology 218:46-55. 10.1016/j.cbpa.2018.01.012

Sathapondecha P, Panyim S, and Udomkit A. 2015. A novel function of bursicon in stimulation of vitellogenin expression in black tiger shrimp, Penaeus monodon. Aquaculture 446:8087. 10.1016/j.aquaculture.2015.04.027

Scott RL, Diao F, Silva V, Park S, Luan H, Ewer J, and White BH. 2020. Non-canonical Eclosion Hormone-Expressing Cells Regulate Drosophila Ecdysis. iScience 23:101108. 10.1016/j.isci.2020.101108

Semaniuk UV, Gospodaryov DV, Feden'ko KM, Yurkevych IS, Vaiserman AM, Storey KB, Simpson SJ, and Lushchak O. 2018. Insulin-Like Peptides Regulate Feeding Preference and Metabolism in Drosophila. Frontiers in Physiology 9:1083.

10.3389/fphys.2018.01083

Sharabi O, Manor R, Weil S, Aflalo ED, Lezer Y, Levy T, Aizen J, Ventura T, Mather PB, Khalaila I, and Sagi A. 2016. Identification and Characterization of an Insulin-Like Receptor Involved in Crustacean Reproduction. Endocrinology 157:928-941. 10.1210/en.2015-1391

Shen J, Zhu D F, Hu Z H, Qi Y Z, and Wang C J. 2011. Molt staging in the swimming crab Portunus trituberculatus. Journal of Fisheries of China 35:1481-1487. 10.3724 /SP.J.1231.2011.17418 
956

957

958

959

960

961

962

963

964

965

966

967

968

969

970

971

972

973

974

975

976

977

978

979

980

981

982

983

984

985

986

987

988

989

990

991

992

993

994

995

Sithigorngul P, Pupuem J, Krungkasem C, Longyant S, Chaivisuthangkura P, Sithigorngul W, and Petsom A. 2002. Seven novel FMRFamide-like neuropeptide sequences from the eyestalk of the giant tiger prawn Penaeus monodon. Comparative Biochemistry and Physiology B-Biochemistry and Molecular Biology 131:325-337. 10.1016/S10964959(01)00499-7

Sithigorngul P, Saraithongkum W, Jaideechoey S, Longyant S, Sithigorngul W. 1998. Novel FMRFamide-like neuropeptides from the eyestalk of the giant freshwater prawn Macrobrachium rosenbergii. Comparative Biochemistry and Physiology Part B Biochemistry and Molecular Biology 120:587-595. 10.1016/S0305-0491(98)10051-2

Skiebe P, and Schneider H. 1994. Allatostatin peptides in the crab stomatogastric nervous system: inhibition of the pyloric motor pattern and distribution of allatostatin-like immunoreactivity. Journal of Experimental Biology 194:195-208. PMID: 7964402

Stafflinger E, Hansen KK, Hauser F, Schneider M, Cazzamali G, Williamson M, and Grimmelikhuijzen CJP. 2008. Cloning and identification of an oxytocin/vasopressin-like receptor and its ligand from insects. Proceedings of the National Academy of Sciences 105:3262-3267. 10.1073/pnas.0710897105

Stangier J. Hilbich C, Beyreuther K., and Keller R. 1987. Unusual cardioactive peptide (CCAP) from pericardial organs of the shore crab Carcinus maenas. Proceedings of the National Academy of Sciences of the United States of America 84:575-579. 10.1073/pnas.84.2.575

Stay B, and Tobe SS. 2007. The Role of Allatostatins in Juvenile Hormone Synthesis in Insects and Crustaceans. Annual Review of Entomology 52:277-299.

10.1146/annurev.ento.51.110104.151050

Stemmler EA, Cashman CR, Messinger DI, Gardner NP, Dickinson PS, and Christie AE. 2007. High-mass-resolution direct-tissue MALDI-FTMS reveals broad conservation of three neuropeptides (APSGFLGMRamide, GYRKPPFNGSIFamide and pQDLDHVFLRFamide) across members of seven decapod crustaean infraorders. Peptides 28:2104-2115. 10.1016/j.peptides.2007.08.019

Sun D, Lyu J, Gao B, Huan P, Cai Y, and Liu P. 2019. Cloning of crustacean cardioactive peptide and its functional verification under low-salt adaptation in swimming crab (Portunus trituberculatus). Journal of Fishery Sciences of China 26:261. 10.3724/sp.j.1118.2019.18207

Sun S, Zhu M, Pan F, Feng J, and Li J. 2020. Identifying Neuropeptide and G Protein-Coupled Receptors of Juvenile Oriental River Prawn (Macrobrachium nipponense) in Response to Salinity Acclimation. Frontiers in Endocrinology 11:623. 10.3389/fendo.2020.00623

Tang B, Zhang D, Li H, Jiang S, Zhang H, Xuan F, Ge B, Wang Z, Liu Y, Sha Z, Cheng Y, Jiang W, Jiang H, Wang Z, Wang K, Li C, Sun Y, She S, Qiu Q, Wang W, Li X, Li Y, Liu Q, and Ren Y. 2020. Chromosome-level genome assembly reveals the unique genome evolution of the swimming crab (Portunus trituberculatus). GigaScience 9:1-10. 10.1093/gigascience/giz161

Peer] reviewing PDF | (2021:05:61499:1:2:NEW 17 Aug 2021) 
996

997

998

999

1000

1001

1002

1003

1004

1005

1006

1007

1008

1009

1010

1011

1012

1013

1014

1015

1016

1017

1018

1019

1020

1021

1022

1023

1024

1025

1026

1027

1028

1029

1030

1031

1032

1033

1034

1035

Tawfik AI, Tanaka S, De Loof A, Schoofs L, Baggerman G, Waelkens E, Derua R, Milner Y, Yerushalmi Y, and Pener MP. 1999. Identification of the gregarization-associated darkpigmentotropin in locusts through an albino mutant. Proceedings of the National Academy of Sciences of the United States of America 96:7083-7087. DOI 10.1073/pnas.96.12.7083

Tinikul Y, Engsusophon A, Kruangkum T, Thongrod S, Tinikul R, and Sobhon P. 2017. Neuropeptide F stimulates ovarian development and spawning in the female giant freshwater prawn, Macrobrachium rosenbergii, and its expression in the ovary during ovarian maturation cycle. Aquaculture 469:128-136. 10.1016/j.aquaculture.2016.11.026

Torfs P,Nieto J, Cerstiaens J,Boon D,Baggerman G,Poulos C,Waelkens E,Derua R,Calderón J,De Loof A ,Schoofs L. 2001. Pyrokinin neuropeptides in a crustacean. Isolation and identification in the white shrimp Penaeus vannamei. European Journal of Biochemistry 268:149-154. 10.1046/j.1432-1327.2001.01858.x

Tran NM, Mykles DL, Elizur A, and Ventura T. 2019. Characterization of G-protein coupled receptors from the blackback land crab Gecarcinus lateralis Y organ transcriptome over the molt cycle. BMC Genomics 20:74. 10.1186/s12864-018-5363-9

Van Hiel MB, Vandersmissen HP, Van Loy T, and Vanden Broeck J. 2012. An evolutionary comparison of leucine-rich repeat containing $G$ protein-coupled receptors reveals a novel LGR subtype. Peptides 34:193-200. 10.1016/j.peptides.2011.11.004

Vandersmissen HP, Van Hiel MB, Van Loy T, Vleugels R, and Vanden Broeck J. 2014. Silencing D. melanogaster lgr1 impairs transition from larval to pupal stage. General and Comparative Endocrinology 209:135-147. 10.1016/j.ygcen.2014.08.006

Vaudry H, Ventura T, Cummins SF, Fitzgibbon Q, Battaglene S, and Elizur A. 2014. Analysis of the Central Nervous System Transcriptome of the Eastern Rock Lobster Sagmariasus verreauxi Reveals Its Putative Neuropeptidome. Plos One 9:e97323. 10.1371/journal.pone.0097323

Veenstra JA. 1989. Isolation and structure of corazonin, a cardioactive peptide from the American cockroach. FEBS Letters 250:231-234. 10.1016/0014-5793(89)80727-6

Veenstra JA. 2000. Mono- and dibasic proteolytic cleavage sites in insect neuroendocrine peptide precursors. Archives of Insect Biochemistry and Physiology 43:49-63. 10.1002/(sici)1520-6327(200002)43:2<49::Aid-arch1>3.0.Co;2-m

Veenstra JA. 2015. The power of next-generation sequencing as illustrated by the neuropeptidome of the crayfish Procambarus clarkii. General and Comparative Endocrinology 224:84-95. 10.1016/j.ygcen.2015.06.013

Veenstra JA. 2016. Similarities between decapod and insect neuropeptidomes. PeerJ 4:e2043. 10.7717/peerj.2043

Veenstra JA. 2020. Gonadulins, the fourth type of insulin-related peptides in decapods. General and Comparative Endocrinology 296:113528. 10.1016/j.ygcen.2020.113528

Ventura T, Bose U, Fitzgibbon QP, Smith GG, Shaw PN, Cummins SF, and Elizur A. 2017. CYP450s analysis across spiny lobster metamorphosis identifies a long sought missing 
1036

1037

1038

1039

1040

1041

1042

1043

1044

1045

1046

1047

1048

1049

1050

1051

1052

1053

1054

1055

1056

1057

1058

1059

1060

1061

1062

1063

1064

1065

1066

1067

1068

1069

1070

1071

1072

1073

1074

1075

1076

link in crustacean development. The Journal of Steroid Biochemistry and Molecular Biology 171:262-269. 10.1016/j.jsbmb.2017.04.007

Verlinden H, Gijbels M, Lismont E, Lenaerts C, Vanden Broeck J, and Marchal E. 2015. The pleiotropic allatoregulatory neuropeptides and their receptors: A mini-review. Journal of Insect Physiollogy 80:2-14. 10.1016/j.jinsphys.2015.04.004

Viet Nguyen T, Ryan LW, Nocillado J, Le Groumellec M, Elizur A, and Ventura T. 2020. Transcriptomic changes across vitellogenesis in the black tiger prawn (Penaeus monodon), neuropeptides and $\mathrm{G}$ protein-coupled receptors repertoire curation. General and Comparative Endocrinology 298:113585. 10.1016/j.ygcen.2020.113585

Vogel KJ, Brown MR, and Strand MR. 2015. Ovary ecdysteroidogenic hormone requires a receptor tyrosine kinase to activate egg formation in the mosquito Aedes aegypti. Proceedings of the National Academy of Sciences 112:5057-5062. 10.1073/pnas.1501814112

Wang C J, Zhu D F, Zhou Q Y, Hu Z H, Xie X and Shen J. 2013. Molt-inhibiting hormone levels and ecdysteroid titer during a molt cycle of Portunus trituberculatus. Acta Hydrobiologica Sinica 37:22-28. 10.7541/2013.22

Webster SG, Wilcockson DC, Mrinalini, and Sharp JH. 2013. Bursicon and neuropeptide cascades during the ecdysis program of the shore crab, Carcinus maenas. General and Comparative Endocrinology 182:54-64. 10.1016/j.ygcen.2012.11.018

Wegener C, Suwansa-ard S, Thongbuakaew T, Wang T, Zhao M, Elizur A, Hanna PJ, Sretarugsa P, Cummins SF, and Sobhon P. 2015. In silico Neuropeptidome of Female Macrobrachium rosenbergii Based on Transcriptome and Peptide Mining of Eyestalk, Central Nervous System and Ovary. Plos One 10:e123848. 10.1371/journal.pone.0123848

Wilcockson DC, and Webster SG. 2008. Identification and developmental expression of mRNAs encoding putative insect cuticle hardening hormone, bursicon in the green shore crab Carcinus maenas. General and Comparative Endocrinology 156:113-125. 10.1016/j.ygcen.2007.12.003

Wu X G, Yao G G, Yang X Z, Cheng Y X, and Wang C L. 2007. A study on the ovarian development of Portunus trituberculatus in East China Sea during the first reproductive cycle. Acta Oceanologica Sinica 29:120-127. 10.3321/j.issn:0253-4193.2007.04.014

Xie X, Zhu D, Yang J, Qiu X, Cui X, and Tang J. 2014. Molecular Cloning of Two Structure Variants of Crustacean Hyperglycemic Hormone (CHH) from the Swimming Crab (Portunus trituberculatus), and Their Gene Expression During Molting and Ovarian Development. Zoological Science 31:802-809. 10.2108/zs 140053

Xu Z, Wei Y, Guo S, Lin D, and Ye H. 2020. Short neuropeptide F enhances the immune response in the hepatopancreas of mud crab (Scylla paramamosain). Fish and Shellfish Immunology 101:244-251. 10.1016/j.fsi.2020.04.007

Xu Z, Zhao M, Li X, Lu Q, Li Y, Ge J, and Pan J. 2015. Transcriptome profiling of the eyestalk of precocious juvenile Chinese mitten crab reveals putative neuropeptides and differentially expressed genes. Gene 569:280-286. 10.1016/j.gene.2015.05.075

PeerJ reviewing PDF | (2021:05:61499:1:2:NEW 17 Aug 2021) 
1077 Yang CH, Belawat P, Hafen E, Jan LY, and Jan YN. 2008. Drosophila egg-laying site selection 1078 as a system to study simple decision-making processes. Science 319:1679-1683.

$1079 \quad 10.1126 /$ science. 1151842

1080 Yang SP, He J G, Sun CB, and Chan SF. 2014. Characterization of the shrimp neuroparsin 1081 (MeNPLP): RNAi silencing resulted in inhibition of vitellogenesis. FEBS Open Bio $1082 \quad$ 4:976-986. 10.1016/j.fob.2014.09.005

1083 Zeng H, Bao C, Huang H, Ye H, and Li S. 2016. The mechanism of regulation of ovarian 1084 maturation by red pigment concentrating hormone in the mud crab Scylla paramamosain. 1085 Animal Reproduction Science 164:152-161. 10.1016/j.anireprosci.2015.11.025

1086 Žitňan D, Kim YJ, Žitňanová I, Roller L, and Adams ME. 2007. Complex steroid-peptide1087 receptor cascade controls insect ecdysis. General and Comparative Endocrinology $1088 \quad 153: 88-96.10 .1016 /$ j.ygcen.2007.04.002

1089 Zmora N, and Chung JS. 2014. A novel hormone is required for the development of reproductive 1090 phenotypes in adult female crabs. Endocrinology 155:230-239. 10.1210/en.2013-1603 


\section{Table 1 (on next page)}

Putative neuropeptide precursors predicted in the central nervous-system transcriptome of $P$. trituberculatus. 
1 Table 1. Putative neuropeptide precursors predicted in the central nervous-system transcriptome of $P$. 2 trituberculatus.

\begin{tabular}{|c|c|c|c|c|c|c|}
\hline Peptide families & $\begin{array}{l}\text { Transcript } \\
\text { ome } \\
\text { size(bp) }\end{array}$ & $\begin{array}{l}\text { ORF } \\
\text { Size } \\
\text { (aa) }\end{array}$ & BLAST matches species & E-value & Ident & $\begin{array}{c}\text { Accession } \\
\text { Num. }\end{array}$ \\
\hline $\mathrm{ACP}$ & 722 & 101 & Scylla olivacea & $3.15 \mathrm{E}-52$ & $95.29 \%$ & Christie,2016 \\
\hline agatoxin-like & 892 & 113 & Penaeus vannamei & $1.00 \mathrm{E}-42$ & $71.68 \%$ & ХР027234917.1 \\
\hline allatostatin $\mathrm{A}$ & 3195 & 659 & Panulirus interruptus & $0.00 \mathrm{E}+00$ & $52.87 \%$ & BAF64528.1 \\
\hline allatostatinB & 1826 & 314 & Portunus trituberculatus & $0.00 \mathrm{E}+00$ & $100 \%$ & QCI34367.1 \\
\hline allatostatinC & 1178 & 149 & Scylla paramamosain & $9.00 \mathrm{E}-81$ & $91.28 \%$ & ALQ28578.1 \\
\hline allatostatinCCC & 1782 & 110 & Scylla paramamosain & $1.00 \mathrm{E}-74$ & $100 \%$ & ALQ28598.1 \\
\hline bursicon- $\alpha$ & 2624 & 148 & Callinectes sapidus & $6.00 \mathrm{E}-102$ & $97.30 \%$ & ACG50067.1 \\
\hline bursicon- $\beta$ & 557 & 141 & Callinectes sapidus & $4.00 \mathrm{E}-79$ & $86.62 \%$ & ACG50066.1 \\
\hline CCAP & 660 & 141 & Portunus trituberculatus & $4.00 \mathrm{E}-100$ & $100 \%$ & AVK43051.1 \\
\hline CHH1 & 1245 & 139 & Portunus trituberculatus & $5.00 \mathrm{E}-100$ & $100 \%$ & ACB46189.1 \\
\hline $\mathrm{CHH} 2$ & 2190 & 135 & Portunus trituberculatus & $1.00 \mathrm{E}-91$ & $100 \%$ & MPC59687.1 \\
\hline MIH & 7048 & 113 & Portunus trituberculatus & $3.00 \mathrm{E}-78$ & $100 \%$ & MPC23433.1 \\
\hline CCHamide1 & 3469 & 189 & Cherax quadricarinatus & $1.00 \mathrm{E}-11$ & $61.40 \%$ & AWK57506.1 \\
\hline CCHamide2 & 784 & 126 & Nephrops norvegicus & $8.00 \mathrm{E}-20$ & $45.54 \%$ & QBX89034.1 \\
\hline $\mathrm{CFSH}$ & 1466 & $\mathrm{C}$ & Callinectes sapidus & $2.00 \mathrm{E}-155$ & $93.72 \%$ & ADO00266.1 \\
\hline corazonin & 905 & 117 & Carcinus maenas & $3.00 \mathrm{E}-48$ & $78.30 \%$ & AVA26882.1 \\
\hline CNMamide & 1348 & 193 & Scylla olivacea & $2.00 \mathrm{E}-117$ & $97.93 \%$ & Christie,2016 \\
\hline CRF-like_DH44 & 1693 & 321 & Cherax quadricarinatus & $1.00 \mathrm{E}-26$ & $77.94 \%$ & AWK57510.1 \\
\hline DH31 & 449 & 111 & Nephrops norvegicus & $8.00 \mathrm{E}-15$ & $68.89 \%$ & QBX89032.1 \\
\hline ETH & 1373 & 136 & Scylla olivacea & $4.06 \mathrm{E}-72$ & $94.11 \%$ & Christie,2016 \\
\hline elevenin & 1803 & 147 & Carcinus maenas & $1.40 \mathrm{E}-75$ & $85.71 \%$ & Christie,2011 \\
\hline GPA2 & 1436 & 120 & Cherax quadricarinatus & $3.00 \mathrm{E}-75$ & $87.50 \%$ & AWK57521.1 \\
\hline GPB5 & 2007 & 228 & Cherax quadricarinatus & $2.00 \mathrm{E}-79$ & $86.51 \%$ & AWK57522.1 \\
\hline GSEFLamide & 1388 & 358 & Homarus americanus & $3.00 \mathrm{E}-146$ & $68.82 \%$ & AYH52118.1 \\
\hline HIGSLYRamide & 2811 & 758 & Cherax quadricarinatus & $3.00 \mathrm{E}-51$ & $37.08 \%$ & AWK57523.1 \\
\hline ILP & 757 & 167 & Nephrops norvegicus & $1.00 \mathrm{E}-26$ & $42.29 \%$ & QBX89050.1 \\
\hline kinin & 2173 & 336 & Scylla paramamosain & $8.00 \mathrm{E}-174$ & $87.78 \%$ & ALQ28594.1 \\
\hline myosuppressin & 806 & 100 & Scylla paramamosain & $1.00 \mathrm{E}-67$ & $100 \%$ & ALQ28580.1 \\
\hline neuroparsin & 2108 & 102 & Portunustrituberculatus & $2.00 \mathrm{E}-67$ & $100 \%$ & AVK43050.1 \\
\hline neuroparsin 2 & 814 & 102 & Scylla paramamosain & $2.00 \mathrm{E}-51$ & $95.88 \%$ & ALQ28589.1 \\
\hline neuroparsin 3 & 1494 & 110 & Nephrops norvegicus & $2.00 \mathrm{E}-12$ & $44.87 \%$ & QBX89061.1 \\
\hline NPF1 & 1454 & 102 & Scylla paramamosain & $3.00 \mathrm{E}-64$ & $96.08 \%$ & ALQ28586.1 \\
\hline NPF2 & 1080 & 131 & Scylla paramamosain & $3.00 \mathrm{E}-62$ & $84.73 \%$ & ALQ28587.1 \\
\hline sNPF & 1498 & 126 & Scylla paramamosain & $2.00 \mathrm{E}-86$ & $96.83 \%$ & ALQ28574.1 \\
\hline vasopressin & 838 & 158 & Portunus pelagicus & $2.00 \mathrm{E}-106$ & $98.10 \%$ & AUT12056.1 \\
\hline orcokinin & 1175 & 181 & Cancer borealis & $3.00 \mathrm{E}-116$ & $93.92 \%$ & ABY82345.1 \\
\hline
\end{tabular}




\begin{tabular}{ccccccc}
\hline PDH1 & 433 & 79 & Nephrops norvegicus & $1.00 \mathrm{E}-25$ & $63.29 \%$ & QBX89064.1 \\
PDH2 & 520 & 78 & Scylla paramamosain & $4.00 \mathrm{E}-27$ & $98.72 \%$ & ALQ28583.1 \\
proctolin & 920 & 94 & Nephrops norvegicus & $1.00 \mathrm{E}-22$ & $64.86 \%$ & QBX89067.1 \\
pyrokinin & 1598 & 338 & Scylla paramamosain & $0.00 \mathrm{E}+00$ & $85.67 \%$ & ALQ28575.1 \\
RPCH & 877 & 110 & Portunus trituberculatus & $3.00 \mathrm{E}-68$ & $100 \%$ & MPC25086.1 \\
RYamide & 880 & 134 & Nephrops norvegicus & $3.00 \mathrm{E}-50$ & $63.04 \%$ & QBX89071.1 \\
SIFamide & 1171 & 78 & Scylla paramamosain & $1.00 \mathrm{E}-47$ & $98.72 \%$ & ALQ28576.1 \\
Sulfakinin & 839 & 165 & Scylla paramamosain & $2.00 \mathrm{E}-40$ & $84.25 \%$ & ALQ28597.1 \\
tachykinin & 915 & 226 & Scylla paramamosain & $6.00 \mathrm{E}-103$ & $82.53 \%$ & ALQ28591.1 \\
trissin & 1341 & 201 & Cherax quadricarinatus & $1.00 \mathrm{E}-31$ & $44.67 \%$ & AWK57547.1 \\
natalisin & 1521 & 375 & Scylla paramamosain & $0.00 \mathrm{E}+00$ & $86.70 \%$ & ALQ28592.1 \\
\hline
\end{tabular}

3 C: C-terminal partial protein.

4 
Figure 1

Identification and molecular characterization of $P$. trituberculatus ACP(A), ALP(B), AST$A(C), A S T-B(D)$ and AST-C/AST-CCC(E).

Schematic diagrams show structures of neuropeptide precursors, including signal peptide (SP), mature peptide, putative cleavage sites, and related peptide. Predicted mature peptide amino acid sequence of AST-A, AST-B, and AST-C/AST-CCChave been aligned using Clustal $\mathrm{X} 2.1$, shown conserved sequence motifs by Jalview 2.10.5 .
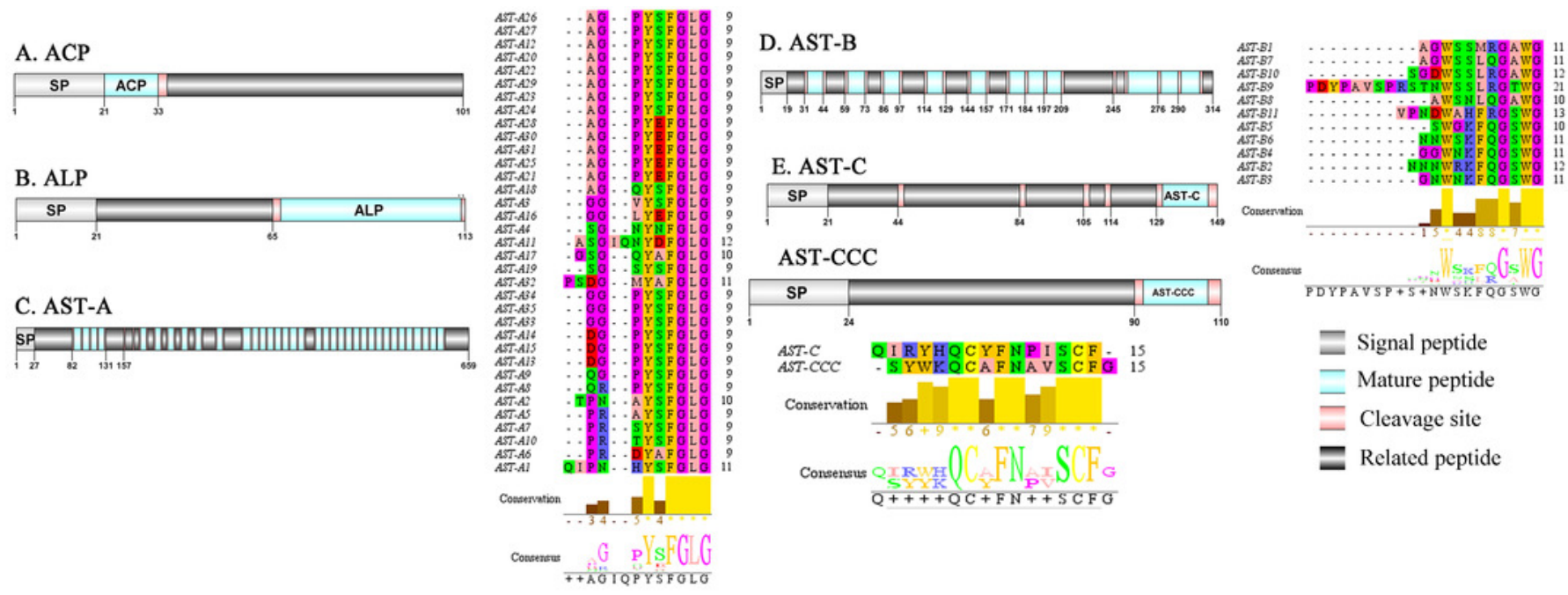


\section{Figure 2}

Identification and molecular characterization of $P$. trituberculatus burscion $\alpha /$ burscion $\beta(A), \operatorname{CCAP}(B), C H H 1 / C H H 2(C)$, and $\mathrm{MIH}(D)$.

Schematic diagrams show structure of neuropeptide precursors, including signal peptide (SP), mature peptide, putative cleavage sites and related peptide. Comparative mature peptide sequence alignment of burscion $\alpha$ and burscion $\beta$ for $P$. trituberculatus with $C$. sapidus and $\mathrm{P}$. argus respectively. Predicted mature peptide amino acid sequence of $\mathrm{CHH} 1 / \mathrm{CHH} 2$ has been aligned using ClustalX2.1, shown conserved sequence motifs by Jalview 2.10.5.
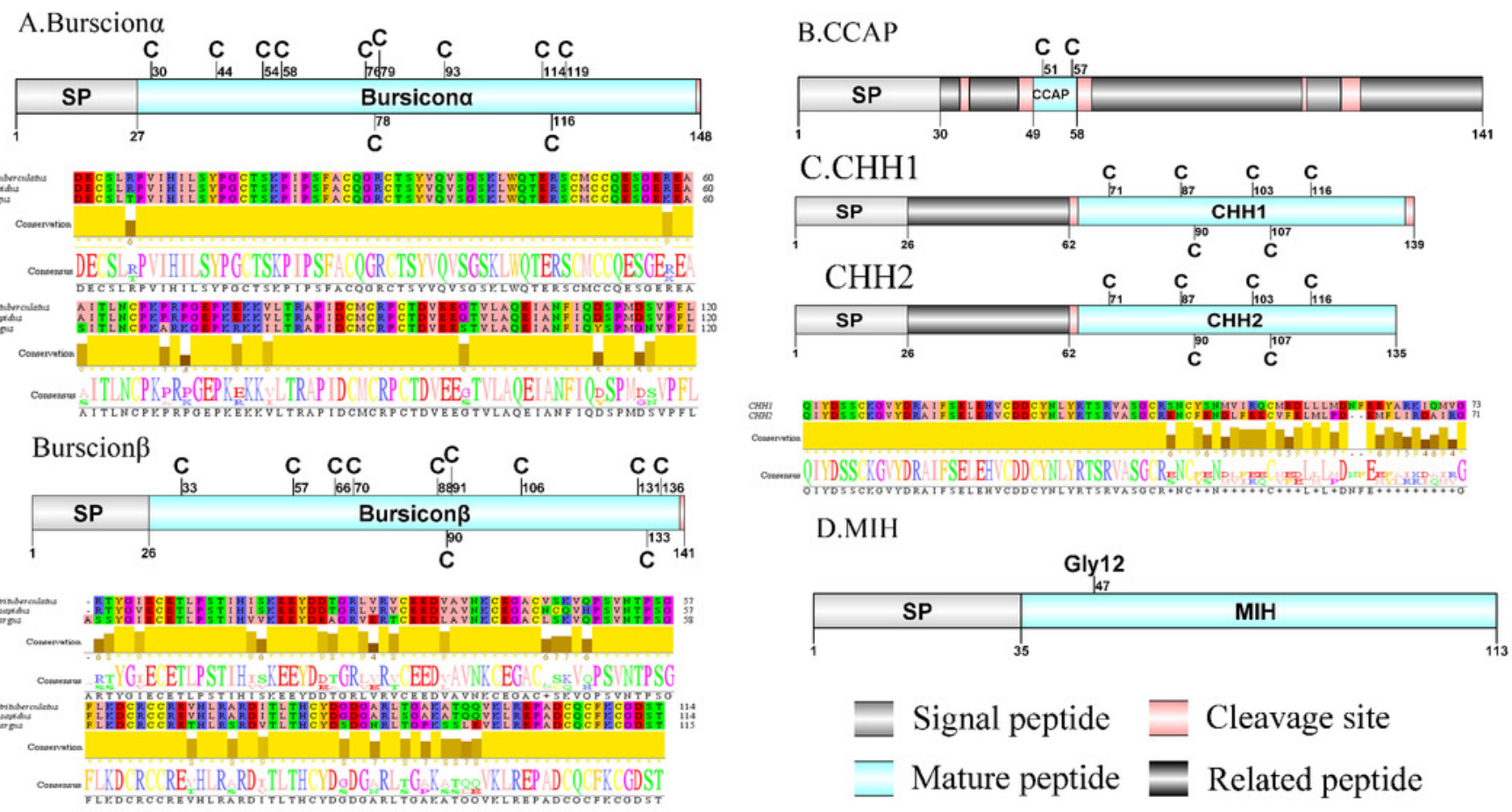


\section{Figure 3}

Identification and molecular characterization of $P$. trituberculatus $\mathrm{CCH} 1 / \mathrm{CCH} 2(\mathrm{~A})$, CFSH(B), $\mathrm{Crz}(\mathrm{C}), \mathrm{CNM}(\mathrm{D}), \mathrm{CRF}-$ like DH44 (E), and DH31(F).

Schematic diagrams show structure of neuropeptide precursors, including signal peptide. (SP), mature peptide, putative cleavage sites, and related peptide. Predicted mature peptide amino acid sequence of $\mathrm{CCH} 1$ and $\mathrm{CCH} 2$ have been aligned using Clustal X2.1, shown conserved sequence motifs by Jalview 2.10.5.

A.CCH1

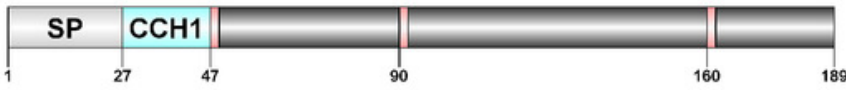

$\mathrm{CCH} 2$

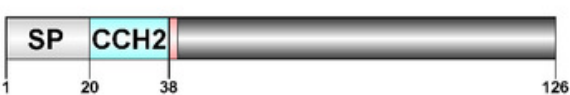

CCH1 HGSVKVG-CLNYGHSCLGAHG 20

CCH2 $\quad-$ VAEGKCSQFGHSCFGAHG 18
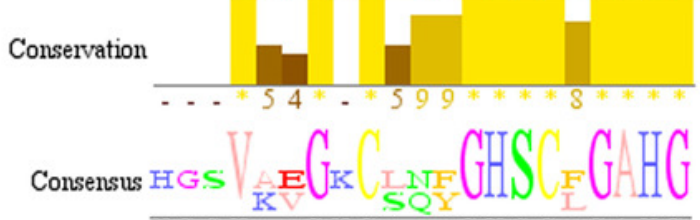

HGSV++GKC +++ GH S C + GAHG

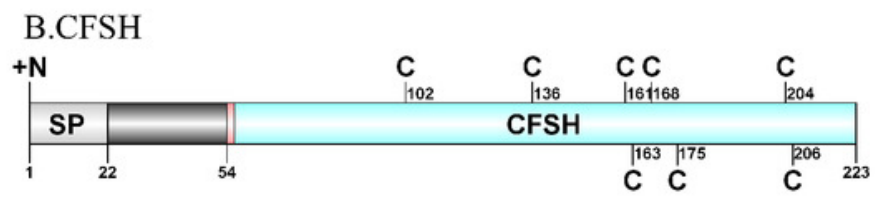

C.Crz
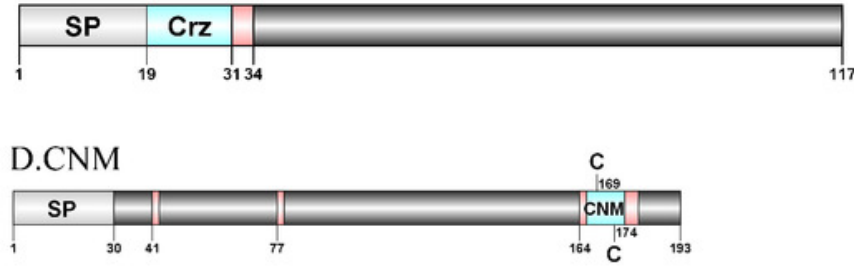

E.CRF-like DH44

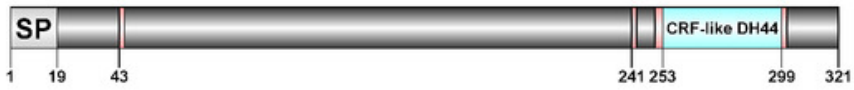

F.DH31

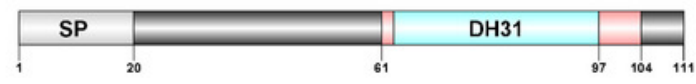

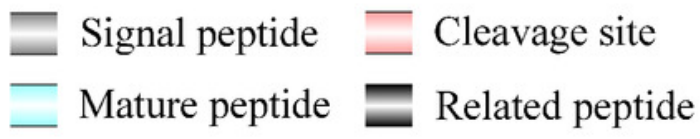


Figure 4

Identification and molecular characterization of $P$. trituberculatus ETH (A), Elevenin (B), GPA2 (C), GPB5 (D), GSEFLamide (E), and HIGSLYRamide (F)

Schematic diagrams show structure of neuropeptide precursors, including signal peptide (SP), mature peptide, putative cleavage sites, and related peptide. Comparative mature peptide sequence alignment of elevenin for $P$. trituberculatus with $C$. quadricarinatus and $H$. americanus. Predicted mature peptide amino acid sequence of GSEFLamide and HIGSLYRamide have been aligned using ClustalX2.1, shown conserved sequence motifs by Jalview. 2.10.5

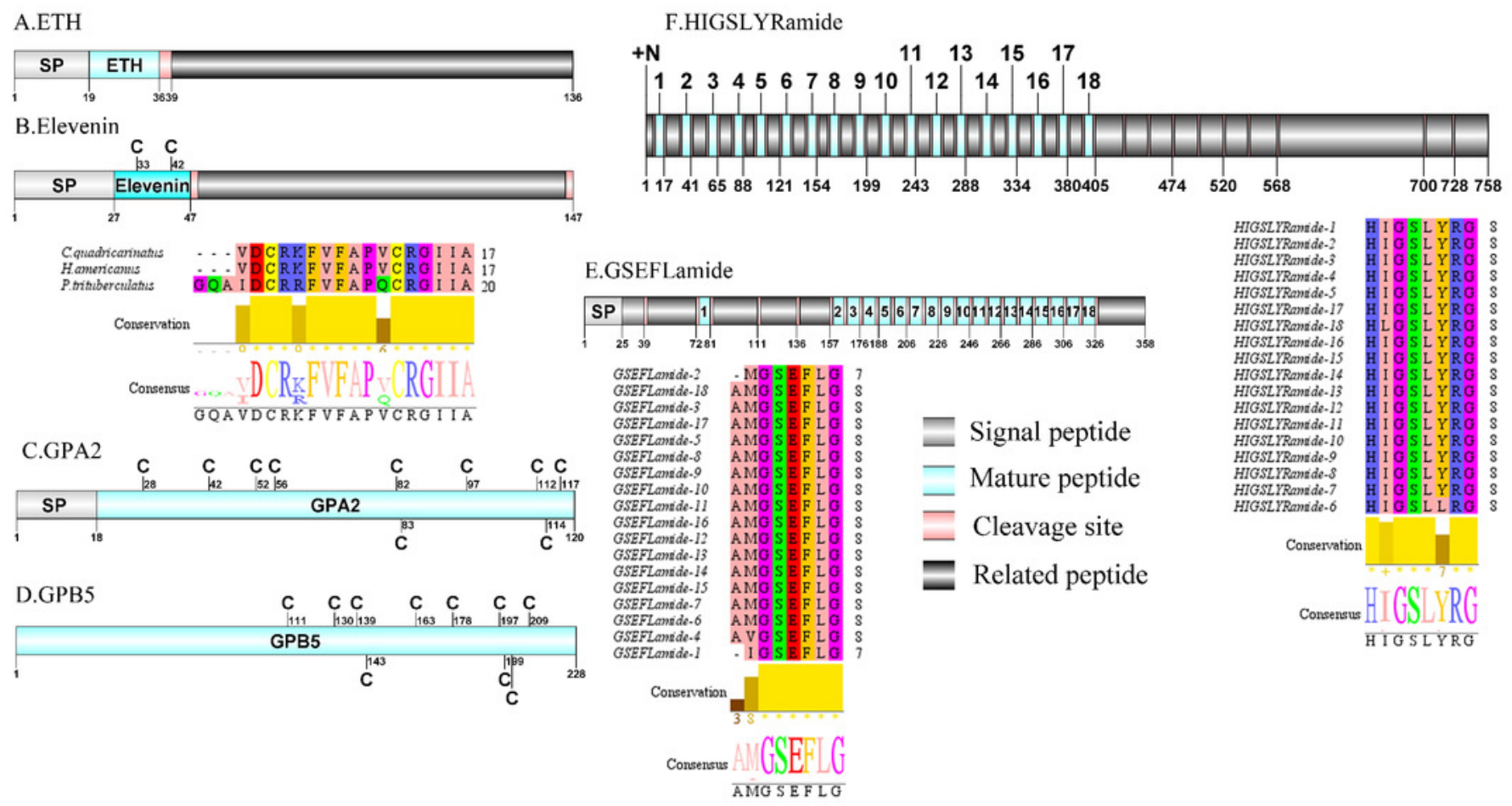




\section{Figure 5}

Identification and molecular characterization of $P$. trituberculatus ILP (A), Kinin (B), Myosuppressin. (C), NP1/NP2/NP3 (D), NPF1/NPF2 (E), and sNPF (F).

Schematic diagrams show structure of neuropeptide precursors, including signal peptide (SP), mature peptide, putative cleavage sites, and related peptide. Predicted mature peptide amino acid sequence of Kinin, NP1/NP2/NP3, NPF1/NPF2, and SNPF have been aligned using Clustal X2.1, shown conserved sequence motifs by Jalview 2.10.5.
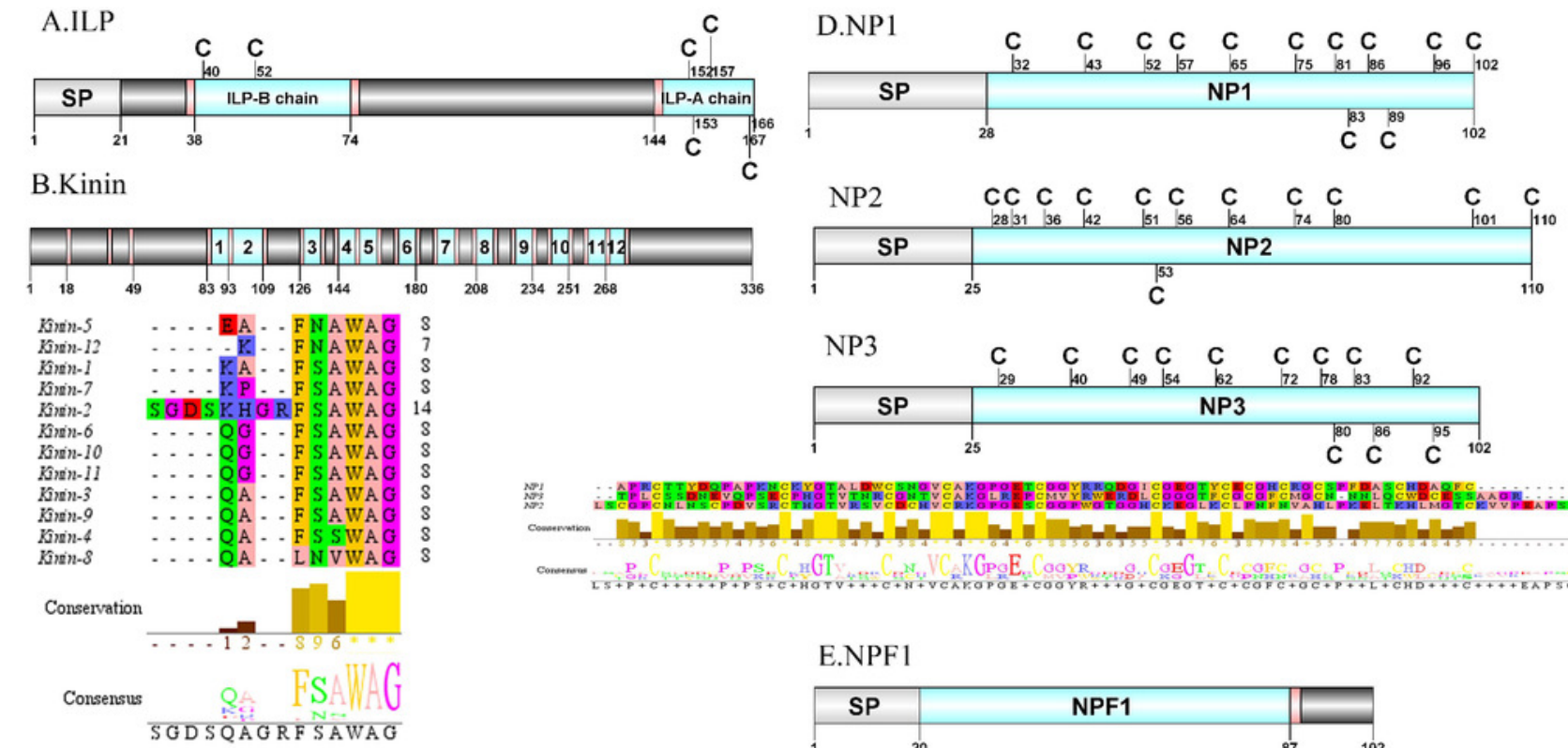

C.Myosuppressin
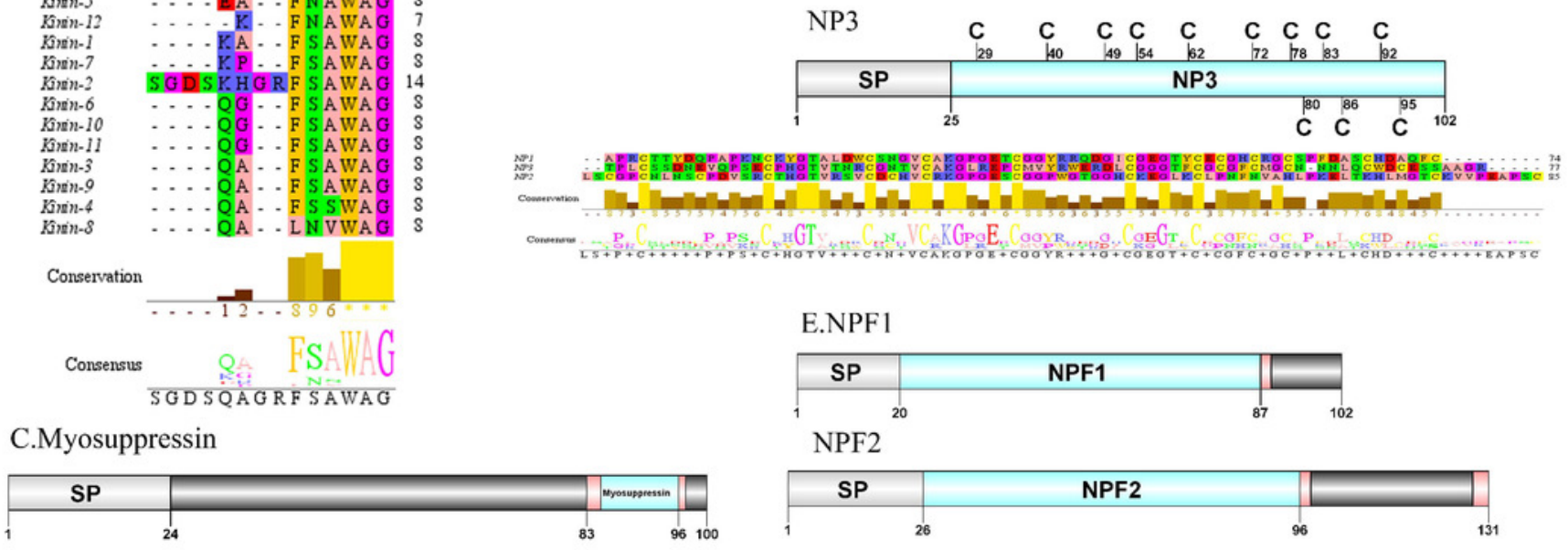

conenes . P P

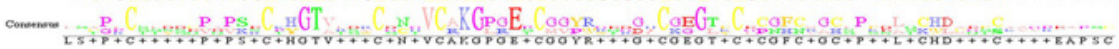

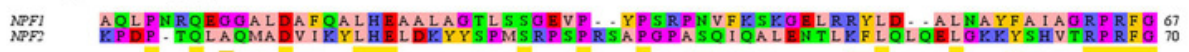

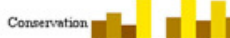

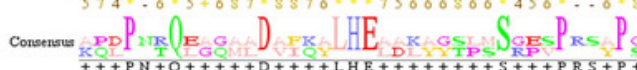

E.NPF1

\begin{tabular}{|l|l|l|} 
SP & NPF1 & \\
\hline 20 & & \\
\hline 87 & 102
\end{tabular}

NPF2

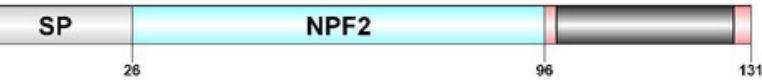

F.sNPF

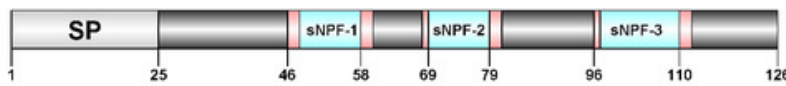

$$
\text { sN }
$$$$
\text { sNPP } s N P
$$

Conservation

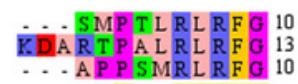
Commens....P.RREG K.DA + + P + LRLRFG
- Signal peptide

— Mature peptide

- Cleavage site

- Related peptide 


\section{Figure 6}

Identification and molecular characterization of $P$. trituberculatus Vasopressin (A), Orcokinin (B), PDH-1/PDH-2 (C), Proctolin(D), Pyrokinin (E), and RPCH(F).

Schematic diagrams show structure of neuropeptide precursors, including signal peptide (SP), mature peptide, putative cleavage sites, and related peptide. Predicted mature peptide amino acid sequence of orcokinin, PDH-1/PDH-2, and pyrokinin have been aligned using Clustal X2.1, shown conserved sequence motifs by Jalview 2.10.5.

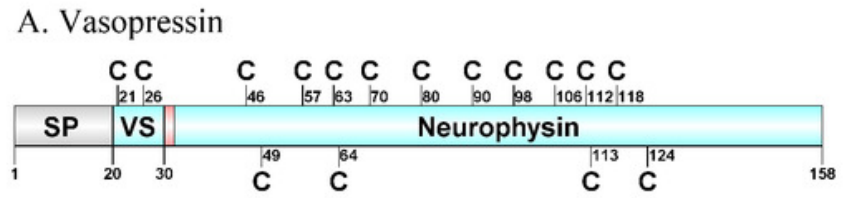

B. Orcokinin
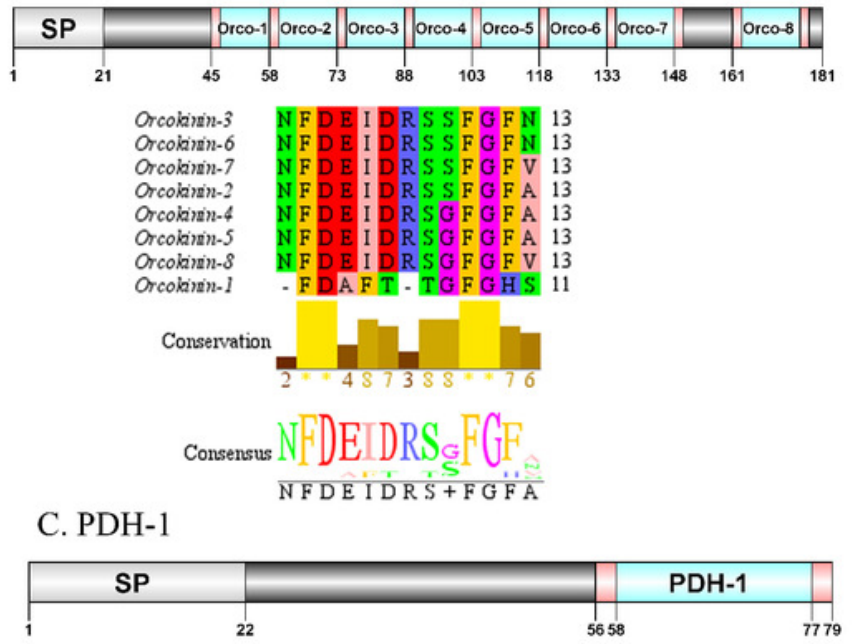

PDH-2

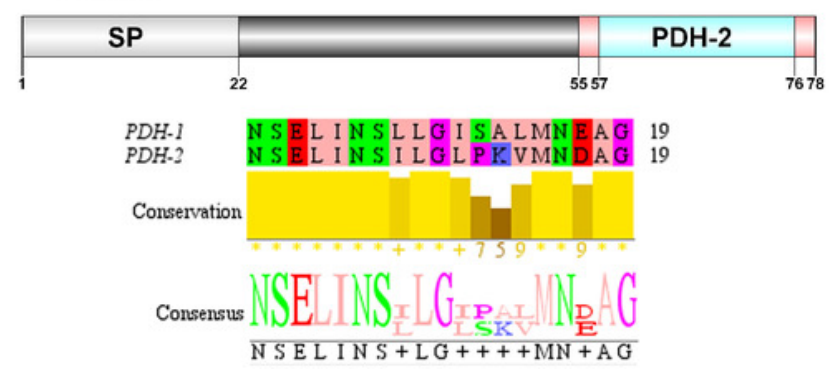

D. Proctolin

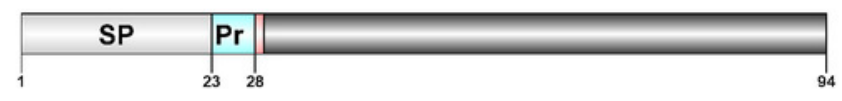

E. Pyrokinin

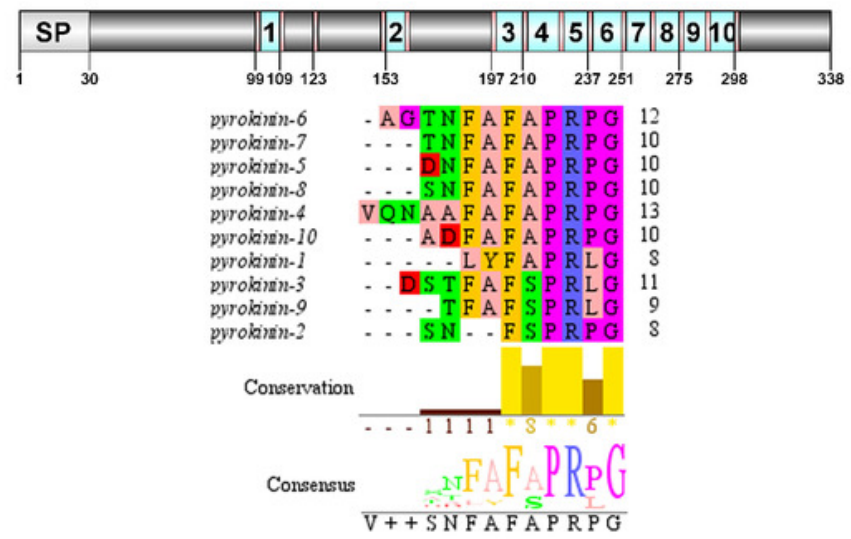

F. $\mathrm{RPCH}$

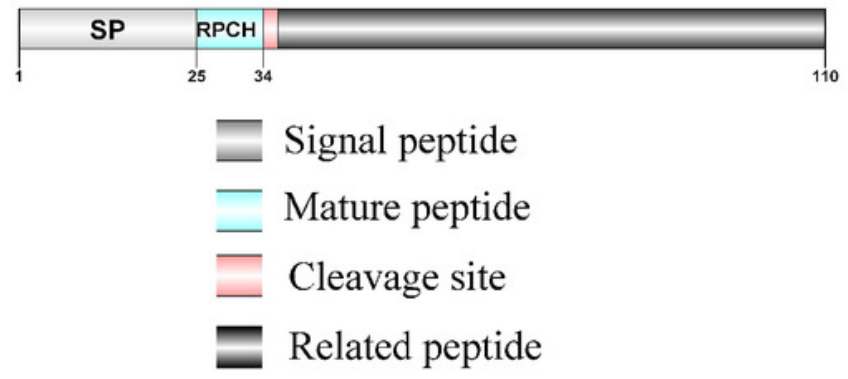




\section{Figure 7}

Identification and molecular characterization of $P$. trituberculatus RYamide (A), SIFamide (B), Sulfakinin (C), Tachykinin (D), Trissin (E), and Natalisin(F).

Schematic diagrams show structure of neuropeptide precursors, including signal peptide (SP), mature peptide, putative cleavage sites, and related peptide. Predicted mature peptide amino acid sequence of RYamide, Sulfakinin, Tachykinin, and natalisin have been aligned using Clustal X2.1, shown conserved sequence motifs by Jalview 2.10.5.

A. RYamide

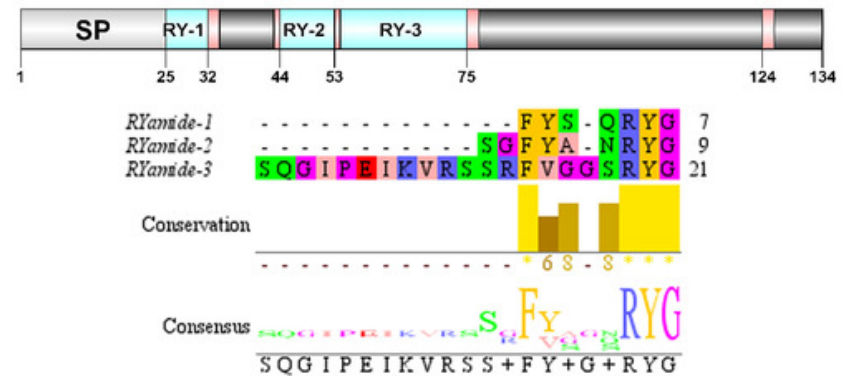

B. SIFamide

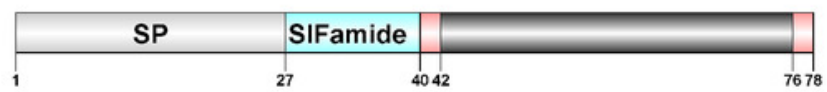

C. Sulfakinin
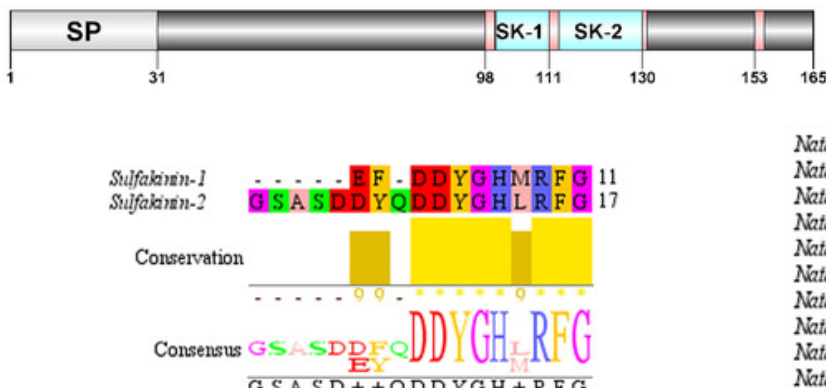

D. Tachykinin

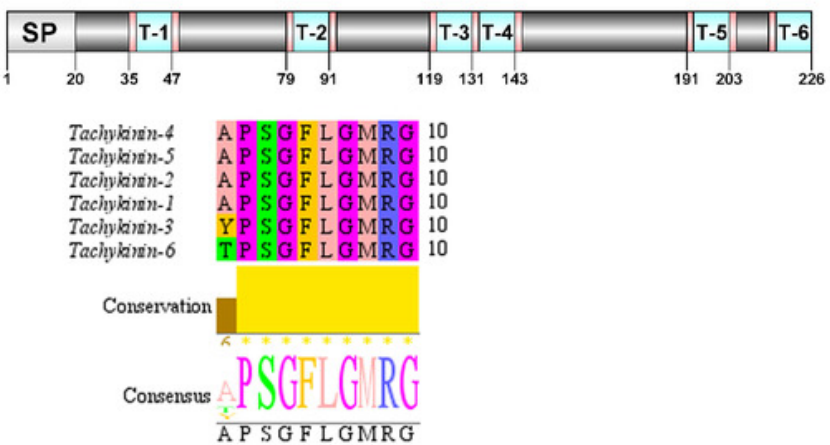

E. Trissin

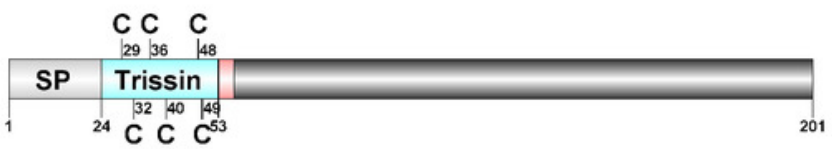

F. Natalisin

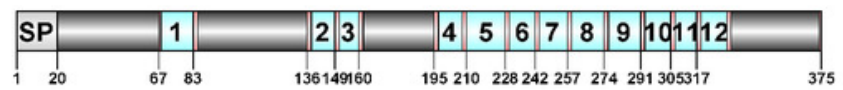

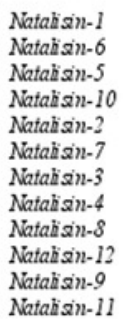

- VEAGY - . GGT TFWVA - RG 15

$\because$ SG...ADN T FWAA RG 12

- PHSGSAASQLA SLWA I. RG 18

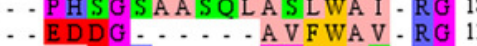

.DGR . . . GPFWA T.RG

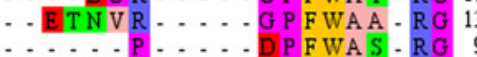

$\cdots$. . . . DPFWAS

SGGEAGT. . . G G FW I S - RG 11

...E DGT ....

QDA T T P T ..... G P YW I A.R

... DP.... PAWT T G RG 10

= Signal peptide

- Mature peptide

Cleavage site

Related peptide

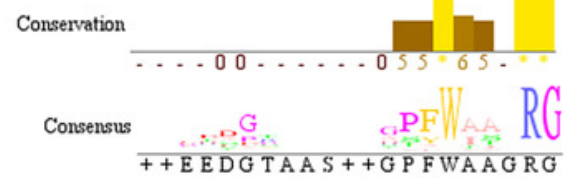




\section{Figure 8}

Phylogeny of the A-family neuropeptide GPCRs. Cladogram of neuropeptide GPCRs showing connections in the clustermap of A-family neuropeptide receptors.

Pt-GPCR, Portunus trituberculatus GPCR; Sp-GPCR, Scylla paramamosain GPCR; Bm-GPCR, Bombyx mori GPCR; Dp-GPCR, Daphnia pulex GPCR; Dm-GPCR, Drosophila melanogaster GPCR; Nn-GPCR, Nephrops norvegicus GPCR;NI-GPCR, Nilaparvata lugens GPCR; Pc-GPCR, Procambarus clarkia GPCR; Sv-GPCR, Sagmariasus verreauxi GPCR; Tu-GPCR, Tetranychus urticae GPCR; Zn-GPCR, Zootermopsis nevadensis GPCR; Tc-GPCR, Tribolium castaneum GPCR. 


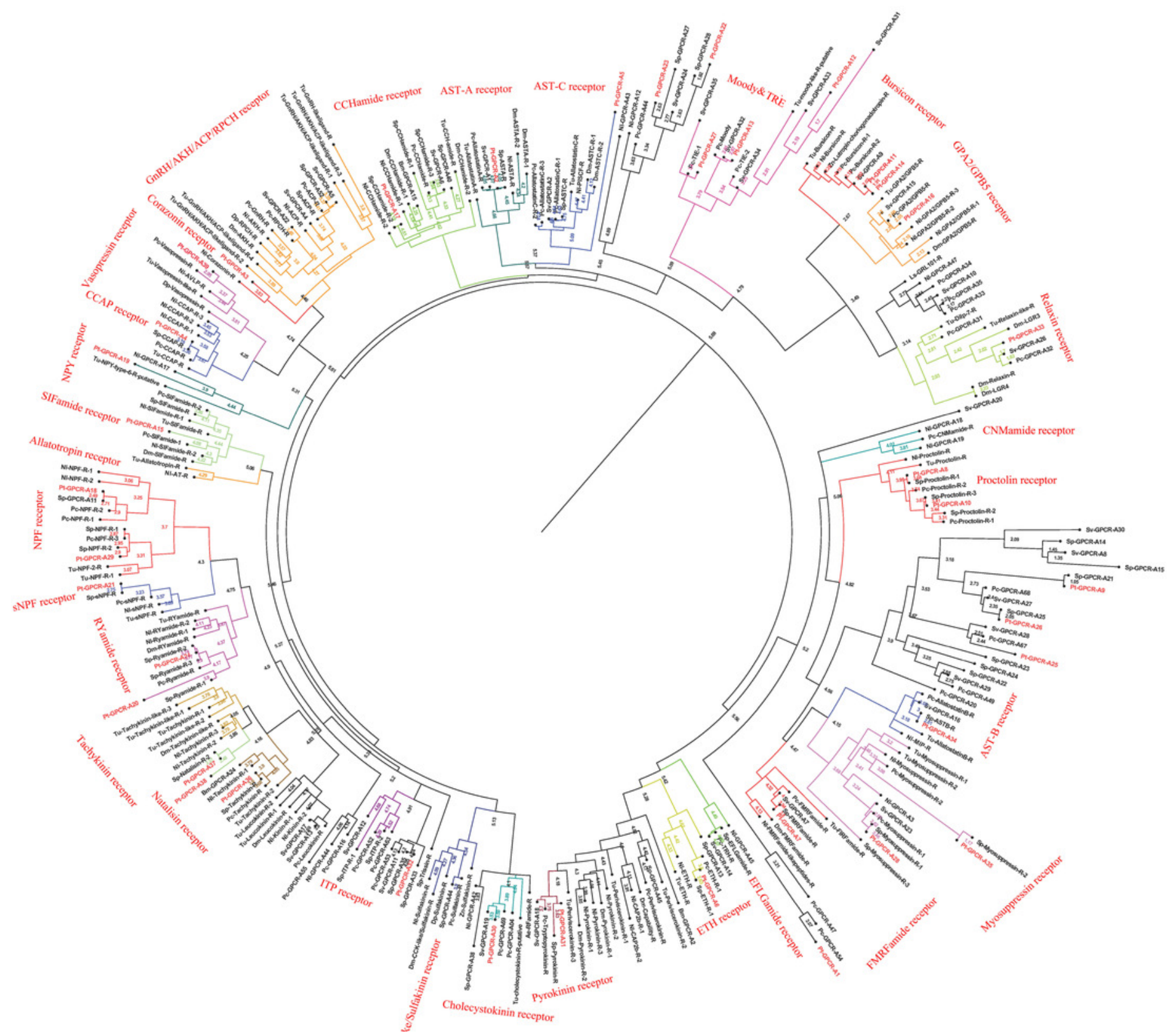


Figure 9

Phylogeny of the B-family neuropeptide GPCRs.

Cladogram of neuropeptide GPCRs showing connections in the clustermap of B-family neuropeptide receptors. Pt-GPCR, Portunus trituberculatus GPCR; Sp-GPCR, Scylla Paramamosain GPCR; Dm-GPCR, Drosophila melanogaster GPCR; Pc-GPCR, Procambarus clarkia GPCR; Sv-GPCR, Sagmariasus verreauxi GPCR; Tu-GPCR, Tetranychus urticae GPCR; Zn-GPCR, Zootermopsis nevadensis GPCR; Mn-GPCR, Macrobrachium nipponense GPCR. 


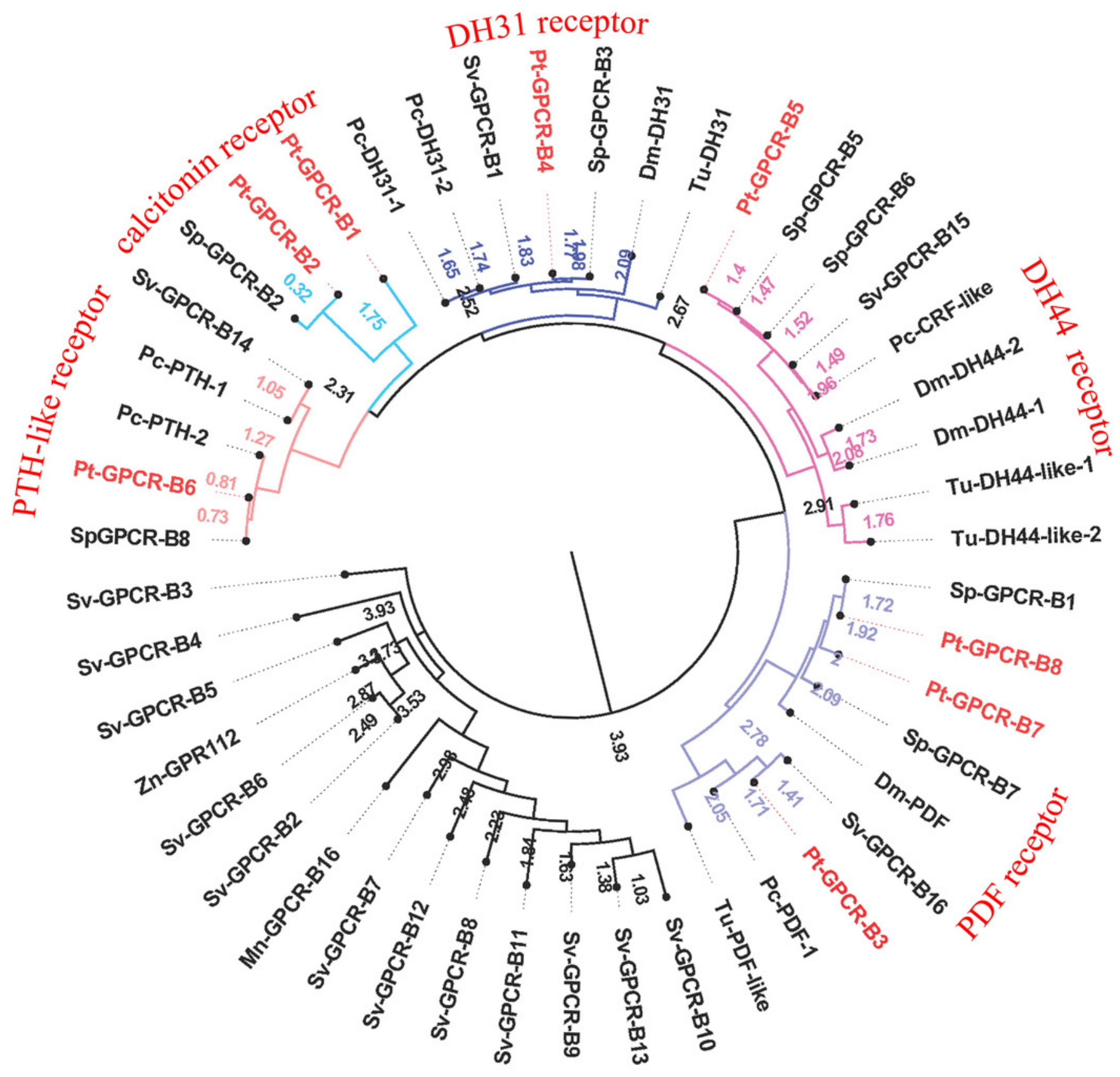




\section{Figure 10}

Tissue distribution of $P$. trituberculatus neuropeptide transcripts.

Thirty-two neuropeptide transcripts were detected in the nine tissues from female $P$. trituberculatus. M:DNA Marker; CG, cerebral ganglia; EG, eyestalk ganglia; Gi, gill; $\mathrm{Hp}$, hepatopancreas; Ht, heart; Ms, muscle; Ov, ovary; VG, ventral ganalia; ; YO, Y-organ; N, negative control (representing no template in PCR). $\beta$-actin as the reference gene.
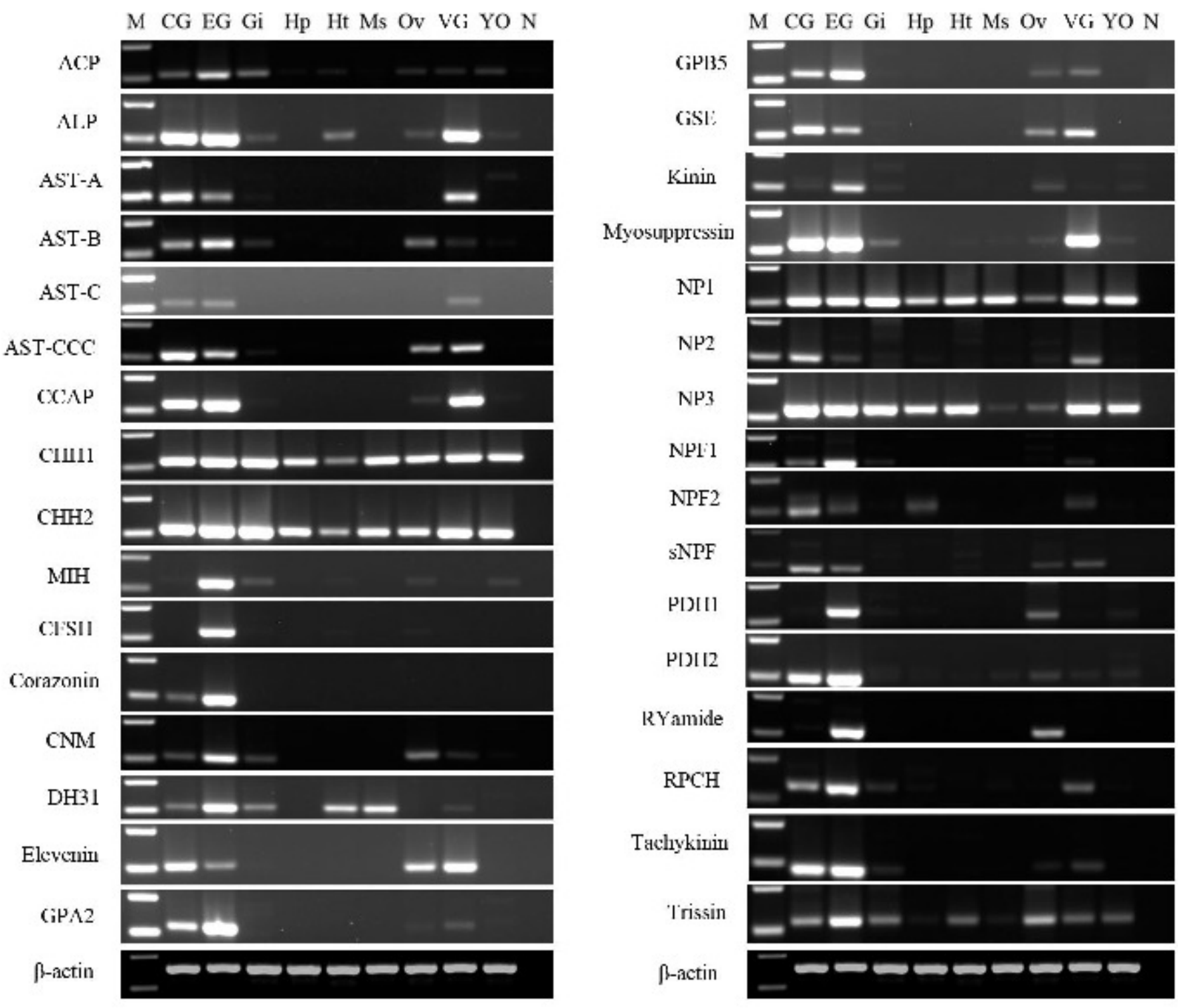


\section{Figure 11}

Tissue distribution of $P$. trituberculatus neuropeptide GPCR transcripts.

Thirty-three neuropeptide GPCR transcripts were detected in nine tissues from female $P$. trituberculatus. M: DNA Marker; CG, cerebral ganglia; EG, eyestalk ganglia; Gi, gill; Hp, hepatopancreas; Ht, heart; Ms, muscle; Ov, ovary; VG, ventral ganalia ; YO, Y-organ; N, negative control (representing no template in PCR). $\beta$-actin as the reference gene.
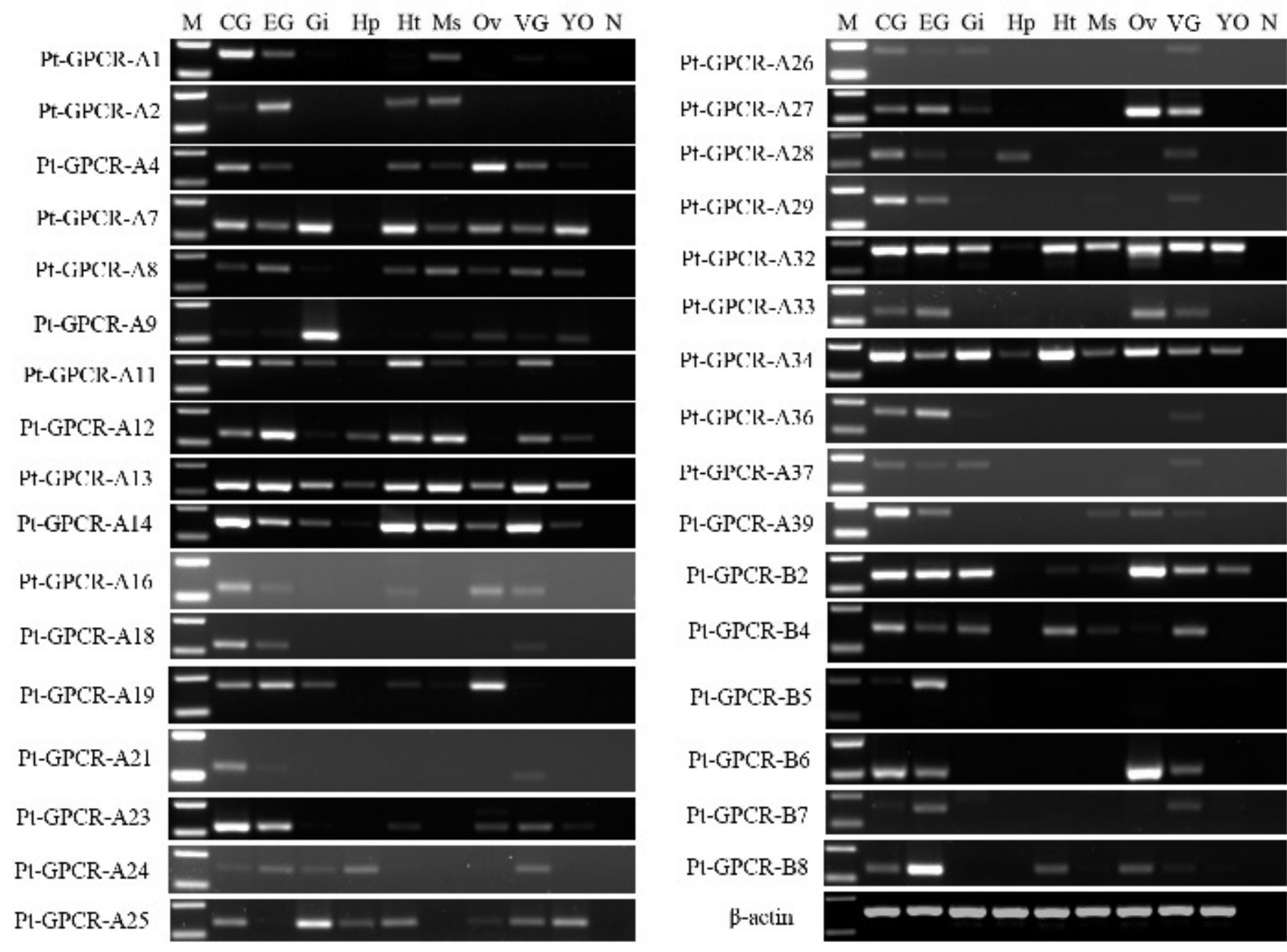